\title{
Overview and Discussion of the OECD/NRC Benchmark Based on NUPEC PWR Subchannel and Bundle Tests
}

\author{
M. Avramova, ${ }^{1}$ A. Rubin, ${ }^{1}$ and H. Utsuno ${ }^{2}$ \\ ${ }^{1}$ Nuclear Engineering Program, The Pennsylvania State University, University Park, PA 16802, USA \\ 2 Japan Nuclear Energy Safety Organization, Kamiyacho MT Building, 4-3-20, Toranomon, Minato, Tokyo 105-0001, Japan \\ Correspondence should be addressed to M. Avramova; mna109@psu.edu
}

Received 7 July 2012; Accepted 31 December 2012

Academic Editor: Annalisa Manera

Copyright (C) 2013 M. Avramova et al. This is an open access article distributed under the Creative Commons Attribution License, which permits unrestricted use, distribution, and reproduction in any medium, provided the original work is properly cited.

The Pennsylvania State University (PSU) under the sponsorship of the US Nuclear Regulatory Commission (NRC) has prepared, organized, conducted, and summarized the Organisation for Economic Co-operation and Development/US Nuclear Regulatory Commission (OECD/NRC) benchmark based on the Nuclear Power Engineering Corporation (NUPEC) pressurized water reactor (PWR) subchannel and bundle tests (PSBTs). The international benchmark activities have been conducted in cooperation with the Nuclear Energy Agency (NEA) of OECD and the Japan Nuclear Energy Safety Organization (JNES), Japan. The OECD/NRC PSBT benchmark was organized to provide a test bed for assessing the capabilities of various thermal-hydraulic subchannel, system, and computational fluid dynamics (CFDs) codes. The benchmark was designed to systematically assess and compare the participants' numerical models for prediction of detailed subchannel void distribution and department from nucleate boiling (DNB), under steady-state and transient conditions, to full-scale experimental data. This paper provides an overview of the objectives of the benchmark along with a definition of the benchmark phases and exercises. The NUPEC PWR PSBT facility and the specific methods used in the void distribution measurements are discussed followed by a summary of comparative analyses of submitted final results for the exercises of the two benchmark phases.

\section{Introduction}

The need to refine the models for best-estimate calculations, based on good-quality experimental data, has been expressed in many recent meetings in the field of nuclear engineering. The needs arising in this respect should not be limited to the currently available macroscopic methods but should be extended to next-generation analysis techniques that focus on more microscopic processes. One of the most valuable databases identified for the thermal-hydraulics modeling was developed by the Nuclear Power Engineering Corporation (NUPEC), Japan, which includes subchannel void fraction and departure from nucleate boiling (DNB) measurements in a representative pressurized water reactor (PWR) fuel assembly [1-3]. From 1987 to 1995, NUPEC performed a series of void measurement tests using full-size mock-up tests for both BWRs and PWRs. Void fraction measurements and departure from nucleate boiling (DNB) tests were performed at NUPEC under steady-state and transient pressurized water reactor (PWR) conditions. Part of this database is made available for an international benchmark activity entitled as the OECD/NRC NUPEC PWR subchannel and bundle tests (PSBT) benchmark [4]. This international project is officially approved by the Japan Ministry of Economy, Trade, and Industry (METI) and US Nuclear Regulatory Commission (NRC) and endorsed by the OECD/NEA. The benchmark team is organized based on the collaboration between Japan and USA.

The fine-mesh high-quality subchannel void fraction and departure from nucleate boiling data encourages the advancement in understanding and modeling complex flow behavior in real rod bundles. Considering that the present theoretical approach is relatively immature, the benchmark specification is designed to systematically assess and compare the participants' analytical models on the prediction of detailed void distributions and DNB. It should be recognized that the purpose of this benchmark is not only the comparison of currently available computational approaches 
but, above all, the encouragement to develop novel nextgeneration approaches that focus on more microscopic processes.

The benchmark consists of two phases with a total of seven exercises, as described below.

(i) Phase I: void distribution benchmark,

(a) exercise 1: steady-state single subchannel benchmark,

(b) exercise 2: steady-state bundle benchmark,

(c) exercise 3: transient bundle benchmark,

(d) exercise 4: Pressure drop benchmark.

(ii) Phase II: DNB benchmark,

(a) exercise 1: steady-state fluid temperature benchmark,

(b) exercise 2: steady-state DNB benchmark,

(c) exercise 3: transient DNB benchmark.

The exercises in phase I of the benchmark are designed to test the codes' ability to predict void distribution in a single subchannel and a bundle under both steady-state and transient conditions as well as to calculate the pressure drop across a bundle.

The exercises in Phase II of the benchmark are designed to test the codes' ability to predict DNB in a bundle assembly under both steady-state and transient conditions, as well as to predict fluid temperatures under these conditions.

\section{Description of PSBT Benchmark}

The benchmark exercises were performed at the NUPEC test facility, shown in Figure 1. The facility consists of a highpressure and high-temperature recirculation loop, a cooling loop, and instrumentation and data recording systems. The recirculation loop consists of a test section, circulation pump, preheater, steam drum (acting as a pressurizer), and a water mixer. The design pressure is $19.2 \mathrm{MPa}$ and the design temperature is $362^{\circ} \mathrm{C}$.

Three different test sections were used to perform the benchmark exercises: one for the subchannel void distribution test, one for the rod bundle void distribution test, and one for the bundle DNB measurements.

The transmission method of gamma-ray was used to measure the density and converted to the void fraction of the gas-liquid two-phase flow. In the DNB measurements, thermocouples were used to determine the heat flux axially along the rod bundle. The thermocouples were attached to the inner surface of the heater rods and determine the boiling transition. The bundle power was increased gradually by fine steps (about $30 \mathrm{~kW}$ ) to the vicinity of DNB power, which was based on preliminary analysis and experience. The occurrence of DNB was confirmed by a rod temperature rise of more than $11^{\circ} \mathrm{C}\left(20^{\circ} \mathrm{F}\right)$ as measured by the thermocouples.

The range of operating conditions for the facility is given in Table 1, and the operating conditions for the four transient scenarios are given in Table 2 .
TABLE 1: Range of NUPEC PWR test facility operating conditions.

\begin{tabular}{lc}
\hline Quantity & Range \\
\hline Pressure & $4.9-16.6 \mathrm{MPa}$ \\
Mass velocity & $550-4150 \mathrm{~kg} / \mathrm{m}^{2} \mathrm{~s}$ \\
Inlet coolant temperature & $140-345^{\circ} \mathrm{C}$ \\
\hline
\end{tabular}

2.1. Subchannel Test Assembly. Four different test assemblies were used to model void distribution in a single subchannel. The subchannels represented by these assemblies are described in Table 3. Figure 2 shows the test section used for the central subchannel void measurement. It simulates one of the subchannel types found in a PWR assembly. Coolant flows in the pressure vessel horizontally through the coolant inlet nozzle located just below the heated section. Similar test sections (Figure 3) were used for the central with thimble, side, and corner subchannel types. The effective heated length is $1555 \mathrm{~mm}$, and the void measurement section begins at $1400 \mathrm{~mm}$ from the bottom of the heated section [4].

2.2. Bundle Test Assembly. Three different test assemblies were used to model void distribution in a rod bundle. The bundles represented by these assemblies are described in Table 4. An electrically heated rod bundle was used to simulate a partial section and full length of a PWR fuel assembly. Figure 4 shows the test section used for the rod bundle void measurements. The effective heated length is $3658 \mathrm{~mm}$. The measurements were performed at three axial elevations: upper-3177 $\mathrm{mm}$, middle-2669 $\mathrm{mm}$, and lower-2216 $\mathrm{mm}$, respectively (please note that the measurement elevations are taken from the bottom of heating section). Coolant flows into the pressure vessel horizontally through the coolant inlet nozzle and down through the section between the flow channel and the pressure vessel. The coolant continues into the flow channel, flowing from the bottom of the pressure vessel up through the test assembly, where the bottom of the heated section is located $630 \mathrm{~mm}$ above the bottom of the pressure vessel.

Figures 5 and 6 show the two different radial power distributions, named A and B, respectively. All powers shown are relative powers.

Table 5 shows the axial power distribution (based on a cosine shape) that was used in the bundle tests.

The test assemblies used for the DNB measurement benchmark are described in Table 6 . The DNB measurements were performed for full-length partial $5 \times 5$ and $6 \times 6$ array rod bundles, which simulate $17 \times 17$ PWR fuel assemblies. Measurements were performed for both steady state and transients. The heater rods used in these bundles are of the same type as those used in the bundles in the void distribution measurements. Three different types of spacer grids were used in these assemblies: simple spacers, nonmixing vane grids, and mixing vane grids [4].

The available experimental data for the steady-state single subchannel benchmark includes CT scanner measurements of the void fraction (subchannel averaged) of four representative subchannel types: typical central, central with a 


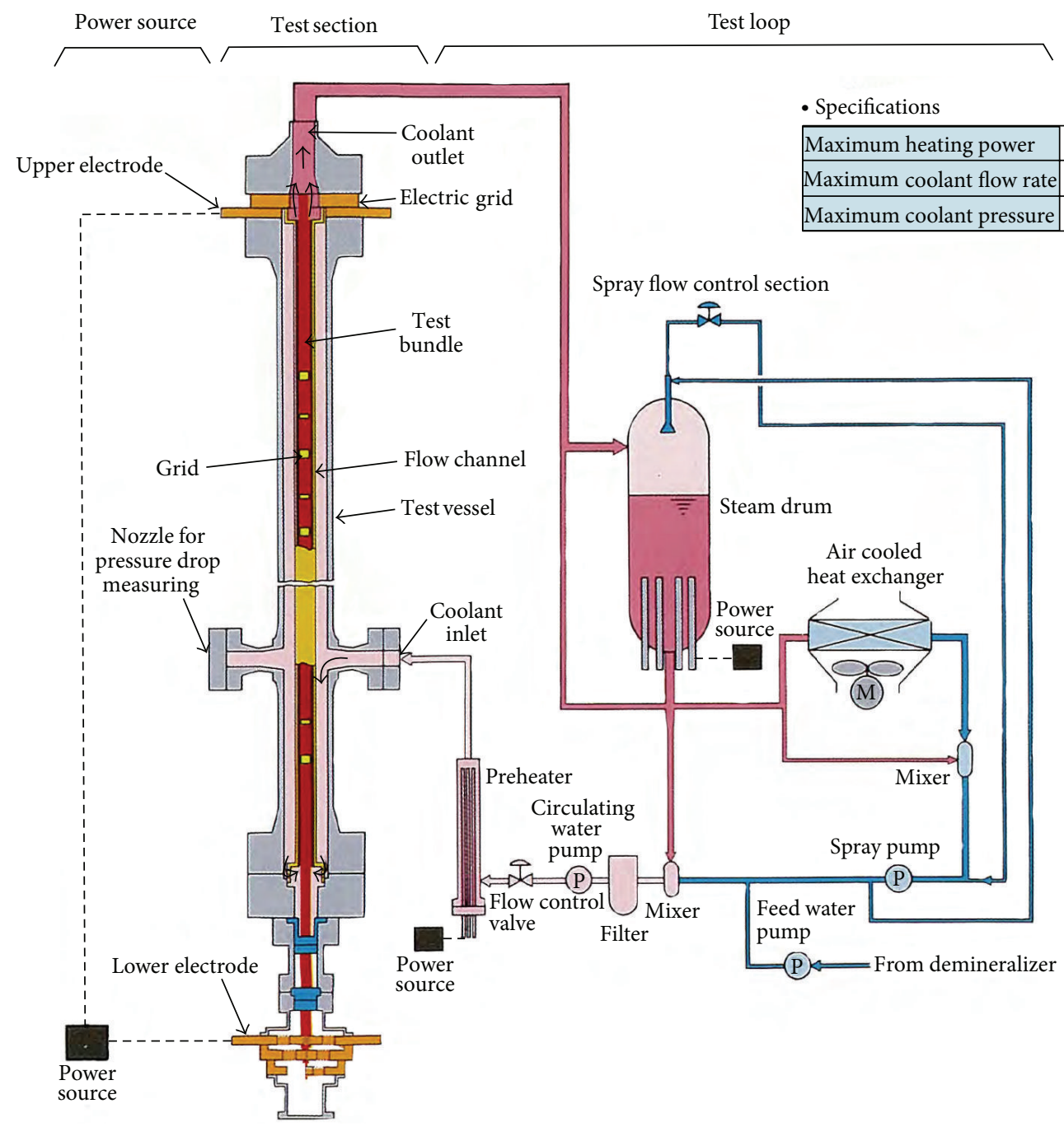

FIGURE 1: System diagram of NUPEC PWR test facility.

TABLE 2: Transient parameters of NUPEC PWR test facility.

\begin{tabular}{lc}
\hline Transient scenario & Transient change \\
\hline Depressurization & $-0.03 \mathrm{MPa} / \mathrm{s}$ \\
Temperature increase & $1^{\circ} \mathrm{C} / \mathrm{s}$ \\
Flow reduction & $-25 \% / \mathrm{s}$ \\
Power increase & $15 \% / \mathrm{s}$ \\
\hline
\end{tabular}

guide tube, side, and corner subchannels and images of the void distribution within two representative subchannel types: typical central and central with guide tube. The data can be used to assess and improve the current models for void generation (subchannel/system and CFD codes) and void distribution within subchannels (CFD codes).

The steady-state bundle benchmark utilizes experimental data that include X-ray densitometer measurements of void fraction (chordal averaged) at three axial elevations. The averaging is over the four central subchannels. The transient bundle benchmark is based on data collected for four anticipated transient scenarios: power increase, flow reduction, depressurization, and temperature increase.

The experimental data for the steady-state DNB benchmark include the power at which departure from nucleate boiling occurs and the corresponding location in the bundle. Measured DNB power for four anticipated transient scenarios-power increase, flow reduction, depressurization, and temperature increase-was made available for the transient DNB benchmark. In addition to the void distribution and DNB power measurements, data is available for the subchannel exit fluid temperature.

2.3. Spacer Grid Data. There were three types of spacers instrumented along the axial length: simple spacer (SS), spacer with non-mixing vanes (NMVs), and spacer with mixing vanes (MVs). The simple spacer has only dimples while NMV and MV have dimples and springs. The grids straps are made out of Inconel 600 alloy. Detailed geometrical description of the grids used in the experiment was not 


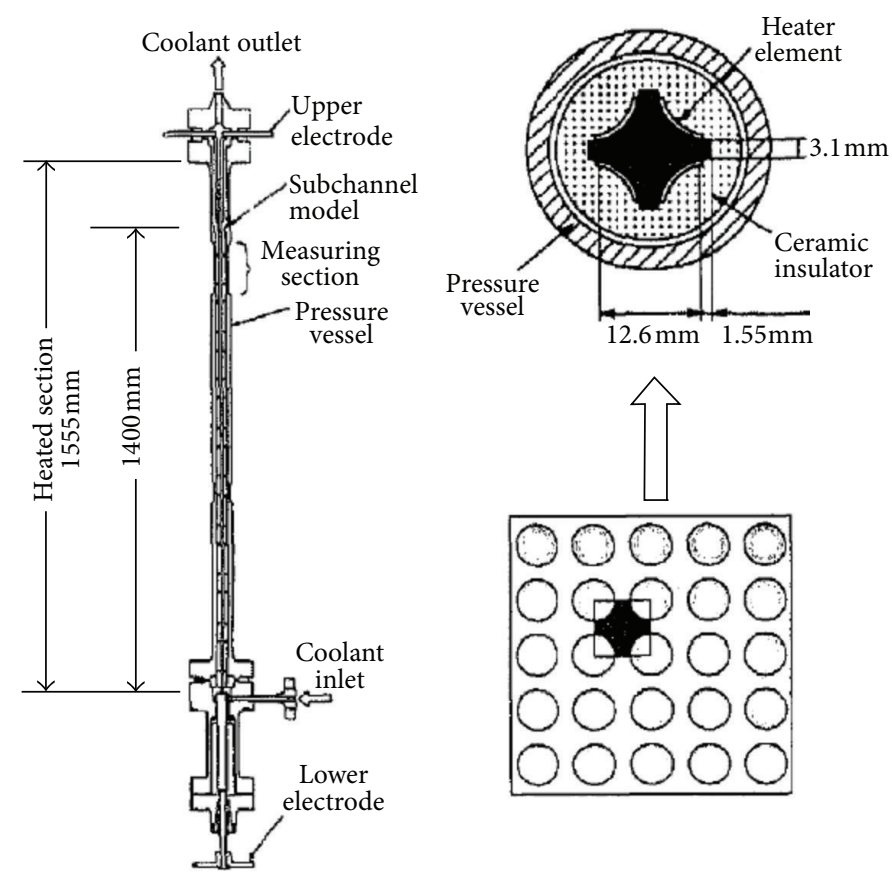

FIGURE 2: Test section for central subchannel void distribution measurement.
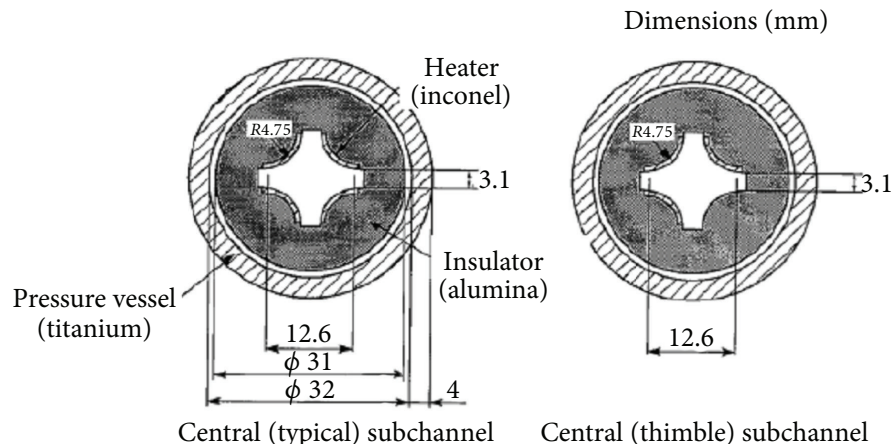

Central (typical) subchannel

Central (thimble) subchannel

S1

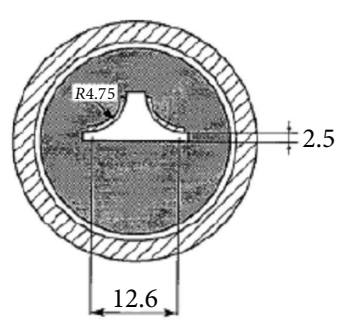

Side subchannel

S3

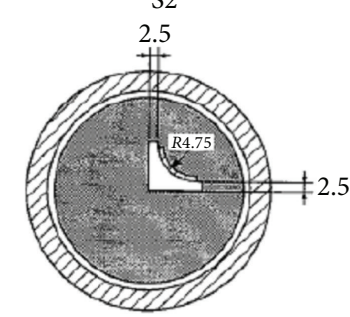

Corner subchannel

S4

FIGURE 3: Cross-sectional view of subchannel test assembly.

available to the benchmark. As a result, the benchmark team, with the assistance of a benchmark participant, was forced to develop a grid model based on the understanding that the grids used in the experiments were similar to grids for which data was readily available. Table 7 summarizes the grid data that was available as part of the benchmark. Figures 7, 8, and 9 provide three-dimensional views of the simple spacer, nonmixing vane, and mixing vane grids. The simple spacer has dimples while the mixing vane and nonmixing vane grids have both dimples and springs. These dimples provide a gap $(\sim 0.1 \mathrm{~mm})$ around each heating rod, which prevents bowing of these rods when they linearly expand at high temperatures.

Table 7 provides the bundle average spacer pressure loss coefficients for the three types of grids. Depending on the 


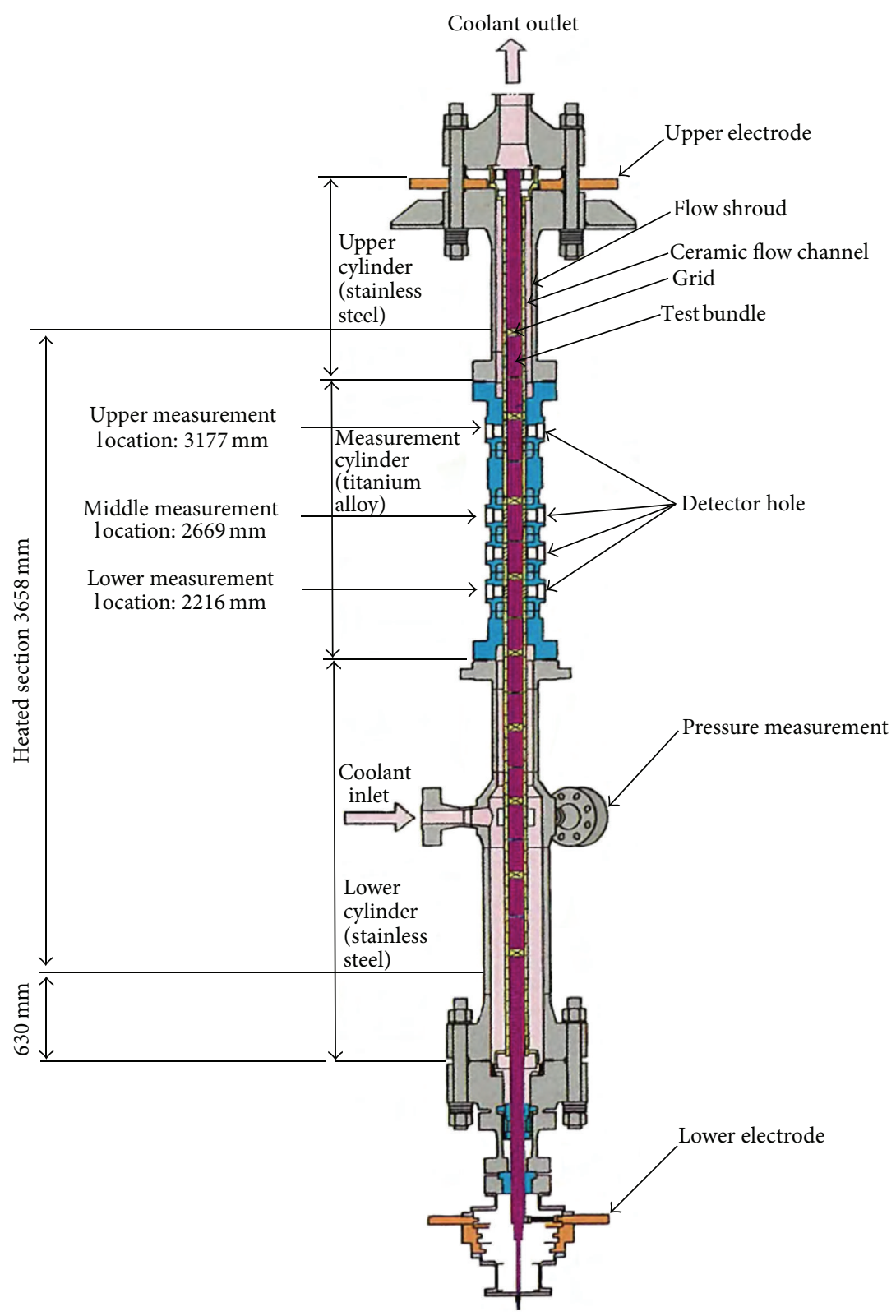

Figure 4: Test section for rod bundle void distribution measurement.

participants' computer code and using the provided spacer data, each participant may choose the subchannel grids loss coefficients or other required input values.

2.4. Heater Rod Data. Table 8 summarizes the material and geometrical properties of the heater rods used in the rod bundle tests. Figure 10 provides a cross-sectional view of the heater rods and gives dimensions.

\subsection{Measurement Techniques}

2.5.1. Void Distribution. A gamma-ray transmission method was used to measure the density of the flow, which was converted to the void fraction of the gas-liquid two-phase flow. Figure 11 shows the procedure used to perform the void fraction measurements for the entire rod bundle. The top half of the figure shows the procedure used to perform the void fraction measurements for a single subchannel. In the subchannel experiments, a narrow gamma-ray beam CT scanner was used to measure the subchannel averaged void fraction, and a wide gamma-ray beam was used to measure the chordal averaged void fraction. For each subchannel type-corner, side, or center-a relationship between the subchannel averaged and the chordal averaged void fractions was individually derived. These relationships were then used to correct the subchannel averaged void fraction measured with the wide beam in the bundle tests.

The void measurement systems shown in Figure 11 consist of gamma-ray sources $\left({ }^{137} \mathrm{Cs}\right)$, detectors, collimators, and 
TABLE 3: Geometry and power shape for subchannel test assemblies for void distribution benchmark.

\begin{tabular}{|c|c|c|c|c|}
\hline Item & & & & \\
\hline Assembly (subjected subch & & & & \\
\hline & S1 & S2 & S3 & S4 \\
\hline Subchannel type & Center (typical) & Center (thimble) & Side & Corner \\
\hline Number of heaters & $4 \times 1 / 4$ & $3 \times 1 / 4$ & $2 \times 1 / 4$ & $1 \times 1 / 4$ \\
\hline Axial heated length (mm) & 1555 & 1555 & 1555 & 1555 \\
\hline Axial power shape & Uniform & Uniform & Uniform & Uniform \\
\hline
\end{tabular}

Black part: subjected subchannel, white circles: heated rod, and circles with dots: thimble rod.

TABLE 4: Geometry and power shape for bundle test assemblies for void distribution benchmark.

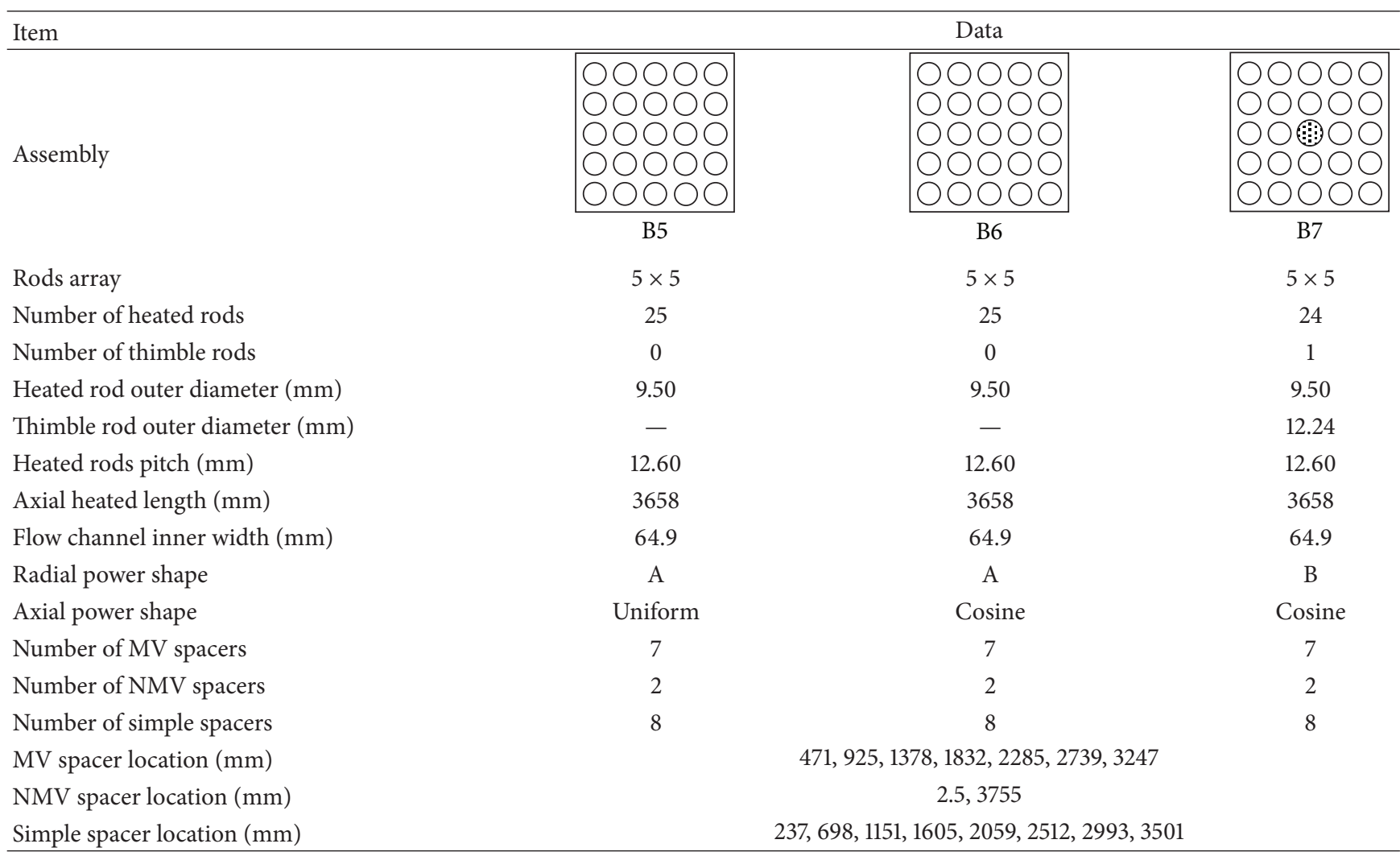

White circles: heated rod and circles with dots: thimble rod.

MV: mixing vane and NMV: non-mixing vane.

Spacer location is the distance from the bottom of heated length to spacer bottom face.

signal processing units. The attenuation of the gamma-rays, which depends on the void fraction, was detected. The intensity of the gamma-ray source was determined to obtain the count rate of the signal processing $\left(30 \times 10^{4} \mathrm{cps}\right)$. The CT scanner system was used to determine the distribution of density/void fraction over the subchannel at steady-state flow and to define the subchannel averaged void fraction. The system was operated by translate/rotate method. At each translation/rotation location, the intensity of gamma-ray attenuated by the object, the so-called "projection data", was detected. An image reconstruction was then performed by a filtered back-projection algorithm to obtain the distribution of the linear attenuation coefficient. A sufficient measuring time was given in order to avoid the effect of the flow motion. Two densitometer systems-in $x$ - and $y$-directions-were used in the chordal averaged void fraction measurements in the single subchannel tests. Each of them consisted of a gamma source and a detector. They were located at the same tables (the same elevation) as CT, which was fixed during the measurements. A multibeam system was used to 


\begin{tabular}{|c|c|c|c|c|}
\hline 0.85 & 0.85 & 0.85 & 0.85 & 0.85 \\
\hline 0.85 & 1 & 1 & 1 & 0.85 \\
\hline 0.85 & 1 & 1 & 1 & 0.85 \\
\hline 0.85 & 1 & 1 & 1 & 0.85 \\
\hline 0.85 & 0.85 & 0.85 & 0.85 & 0.85 \\
\hline
\end{tabular}

FIGURE 5: Radial power distribution A.

\begin{tabular}{|c|c|c|c|c|}
\hline 0.85 & 0.85 & 0.85 & 0.85 & 0.85 \\
\hline 0.85 & 1 & 1 & 1 & 0.85 \\
\hline 0.85 & 1 & 0 & 1 & 0.85 \\
\hline 0.85 & 1 & 1 & 1 & 0.85 \\
\hline 0.85 & 0.85 & 0.85 & 0.85 & 0.85 \\
\hline
\end{tabular}

Figure 6: Radial power distribution B.

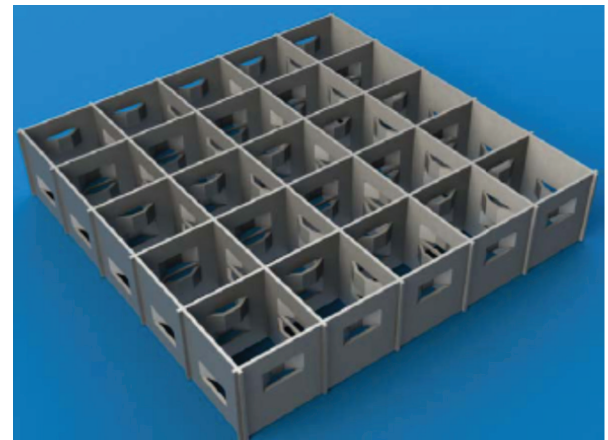

FigURE 7: View of simple spacer grid.

measure each subchannel void fraction of the rod bundle. Six transmission data of $x$-direction and six transmission data of $y$-direction between the rod and rod/channel wall were used to reconstruct the void fraction of the 36 subchannels by an iterative method. These subchannel void fractions corresponded to the chordal measurements of the single subchannel tests. The relationships between the subchannel averaged void fraction and the chordal averaged void fraction obtained in the single subchannel tests were used to determine the

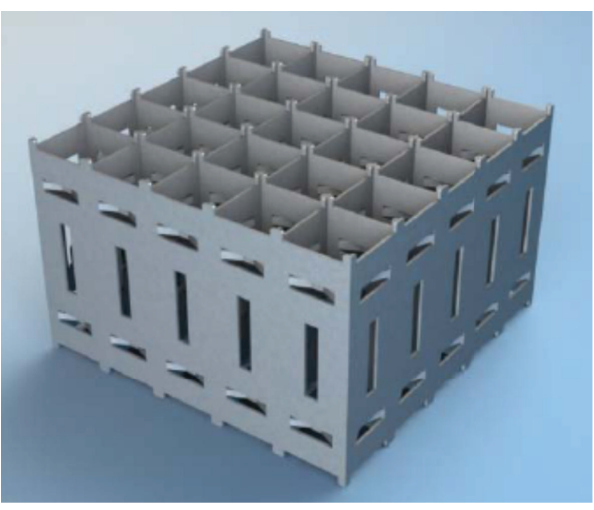

FIGURE 8: View of nonmixing vane spacer grid.

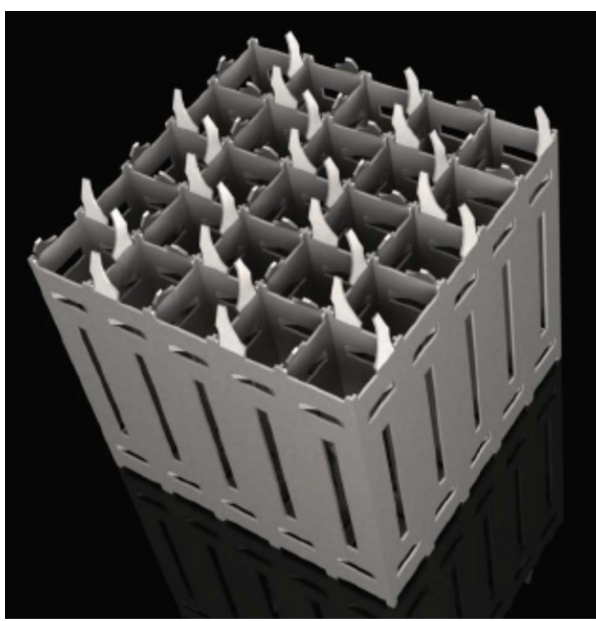

FIGURE 9: View of mixing vane spacer grid.

subchannel averaged void fractions in the rod bundle tests. Such measurements were performed simultaneously at three axial elevations. Table 9 shows the accuracy of the various parameters involved in the experiment. Table 10 summarizes the sources of error in the experiment.

Figure 12 illustrates the relationship between chordal and CT averaged densities as a function of pressure. It was used to determine the uncertainties inherent in the void measurements and to correct the measured values based on the pressure of the test case. The correlation between the chordal and CT averaged values is given by the best-fit curves and was introduced for the high- and low-pressure conditions, respectively. The reference averaged density was $500 \mathrm{~kg} / \mathrm{m}^{3}$. The uncertainty of the correlation was determined to be less than $18 \mathrm{~kg} / \mathrm{m}^{3}$, which was regarded as three standard deviations $(3 \sigma)$. Therefore, one standard deviation $(1 \sigma)$ is $6 \mathrm{~kg} / \mathrm{m}^{3}$. Table 11 shows the number of gamma-ray beams used in the fluid density measurement for both subchannel and rod bundle exercises. Table 12 shows the amount of time required to perform the density measurement.

2.5.2. Departure from Nucleate Boiling. The bundle power was gradually increased in fine steps to the expected vicinity 


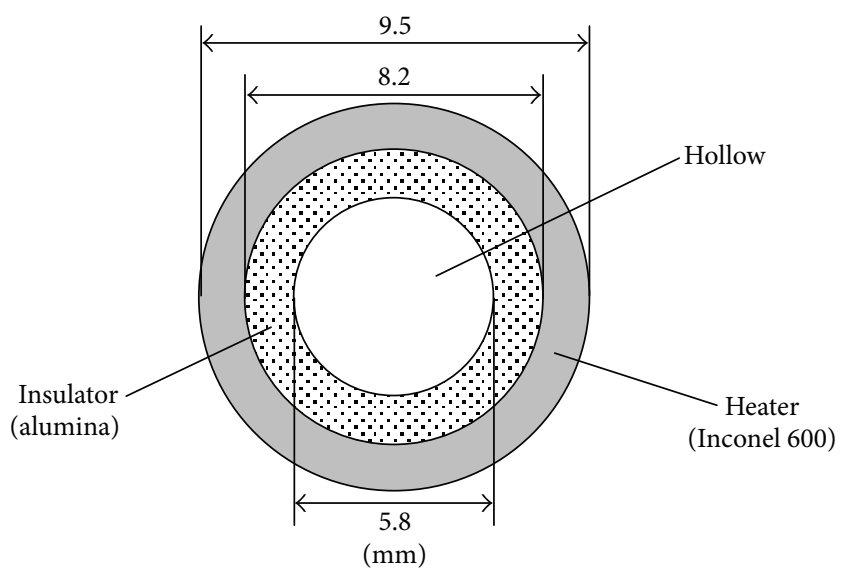

Figure 10: Cross-sectional View of Heater Rod.

TABLE 5: Cosine axial power distribution.

\begin{tabular}{|c|c|}
\hline Node & Relative power \\
\hline \multicolumn{2}{|c|}{ (Bottom) } \\
\hline 1 & 0.42 \\
\hline 2 & 0.47 \\
\hline 3 & 0.56 \\
\hline 4 & 0.67 \\
\hline 5 & 0.80 \\
\hline 6 & 0.94 \\
\hline 7 & 1.08 \\
\hline 8 & 1.22 \\
\hline 9 & 1.34 \\
\hline 10 & 1.44 \\
\hline 11 & 1.51 \\
\hline 12 & 1.55 \\
\hline 13 & 1.55 \\
\hline 14 & 1.51 \\
\hline 15 & 1.44 \\
\hline 16 & 1.34 \\
\hline 17 & 1.22 \\
\hline 18 & 1.08 \\
\hline 19 & 0.94 \\
\hline 20 & 0.80 \\
\hline 21 & 0.67 \\
\hline 22 & 0.56 \\
\hline 23 & 0.47 \\
\hline 24 & 0.42 \\
\hline (Top) & \\
\hline
\end{tabular}

of DNB, which was based on previous analysis operator experience. The onset of DNB was confirmed by a rod temperature rise greater than $11^{\circ} \mathrm{C}\left(20^{\circ} \mathrm{F}\right)$ as measured by the thermocouples seen in Figure 13. The DNB power is defined as the power corresponding to the step immediately preceding the step in which this temperature rise is seen. The accuracy of the process parameters involved in this process is seen in Table 13. The exit fluid temperatures were measured by the thermocouples shown in Figure 14.

2.6. Experimental Data Analysis. Based on the participants feedback, several studies were performed to determine the validity of the benchmark data. These included (1) study performed on recalculation of the void fraction, (2) study performed on calculation of the quality, (3) study performed on the subchannel CT masking, and (4) study performed on bundle test section downcomer region. In this paper, the studies (1), (2), and (4) performed by the benchmark team are presented.

2.6.1. Recalculation of Void Fraction. At the first PSBT workshop, it was noted by several participants that the "measured" void fractions (which were actually calculated from measured density data) were not consistent with void fractions calculated using the measured densities. As a result, a study was performed to recalculate the void fraction and the quality for each test case in the void distribution benchmark.

Solving the standard equation for mixture density $(\bar{\rho}=$ $\left.\alpha \rho_{g}+(1-\alpha) \rho_{f}\right)$ for the void fraction gives $\alpha=\left(\bar{\rho}-\rho_{f}\right) /\left(\rho_{g}-\right.$ $\left.\rho_{f}\right)$, where the liquid and vapor densities $\left(\rho_{f}\right.$ and $\rho_{g}$, resp.) are assumed to be at saturation and the mixture density is taken from the benchmark data. After the recalculation (see Figure 15), it was noted that the measured void fraction was consistently higher than the recalculated void fraction. This recalculation was only performed for the subchannel test cases since those are the only test cases for which fluid density data was available.

2.6.2. Calculation of Quality. Upon completion of the study performed on void distribution, the benchmark team began a study of the calculation of quality based on the experimentally determined densities.

It is recalled that the quality can be expressed using mixture enthalpy as $x=\left(h_{\text {mix }}-h_{f}\right) /\left(h_{g}-h_{f}\right)$, where $h_{f}$ and $h_{g}$ are the liquid and vapor enthalpies, respectively. A number of different expressions were derived to determine the mixture enthalpy in the test sections assuming conservation of energy. After verifying that the axial power distribution was normalized for both the uniform and cosine power shapes, the following equations were obtained.

All four subchannel test sections utilized a uniform axial power distribution. Thus, for all subchannel assemblies, the mixture enthalpy at the measurement section can be given by

$$
\begin{aligned}
h_{\text {mix }}= & h_{\mathrm{in}}+\left(\frac{1400 \mathrm{~mm}}{1555 \mathrm{~mm}}\right) \times \mathrm{Q}[\mathrm{kW}] \\
& \times \frac{3600[\mathrm{~s} / \mathrm{h}]}{\left(A\left[\mathrm{~m}^{2}\right] G\left[\mathrm{~kg} / \mathrm{m}^{2} \mathrm{~h}\right]\right)} .
\end{aligned}
$$

Figure 16 shows the resulting deviation of the experimental quality from the recalculated quality. 
TABLE 6: Test assemblies for DNB measurements.

\begin{tabular}{lcccc}
\hline Assembly & Reference fuel type & Rods array & Type of cell & \multicolumn{2}{c}{ Power distribution } \\
& & & Radial & Axial \\
\hline A0 & & Typical cell & Uniform \\
A1 & $5 \times 5$ & Typical cell & C & Uniform \\
A2 & & Typical cell & A & Uniform \\
A3 & \multirow{2}{*}{$6 \times 6$} & Typical cell & D & Uniform \\
A4 & & Typical cell & Cosine \\
A8 & & Thimble cell & Cosine \\
A11 & $5 \times 5$ & Typical cell & Cosine \\
A12 & & Thimble cell & A & B \\
\hline
\end{tabular}

TABLE 7: Bundle average spacer pressure loss coefficients.

\begin{tabular}{lc}
\hline Spacer type & Loss coefficient \\
\hline Simple spacer (SS) & 0.4 \\
Nonmixing vanes (NMVs) spacer & 0.7 \\
Mixing vanes (MVs) spacer & 1.0 \\
\hline
\end{tabular}

TABLE 8: Properties of heater rods.

\begin{tabular}{ll}
\hline Item & Data \\
\hline Heater & \\
Outer diameter $(\mathrm{mm})$ & 9.5 \\
Thickness $(\mathrm{mm})$ & 0.65 \\
Material & Inconel 600 \\
Heating method & Direct heating \\
\hline Insulator & \\
Outer diameter $(\mathrm{mm})$ & 8.2 \\
Inner diameter $(\mathrm{mm})$ & 5.8 \\
Material & Alumina \\
\hline
\end{tabular}

Assembly B5 utilized a uniform axial power distribution, so the mixture enthalpies at the three measurement locations can be given as

$$
\begin{aligned}
h_{\text {mix }}= & h_{\mathrm{in}}+\left(\frac{2216 \mathrm{~mm}}{3658 \mathrm{~mm}}\right) \times \mathrm{Q}[\mathrm{kW}] \\
& \times \frac{3600[\mathrm{~s} / \mathrm{h}]}{\left(A\left[\mathrm{~m}^{2}\right] G\left[\mathrm{~kg} / \mathrm{m}^{2} \mathrm{~h}\right]\right)} \quad \text { (lower elevation) }, \\
h_{\text {mix }}= & h_{\mathrm{in}}+\left(\frac{2669 \mathrm{~mm}}{3658 \mathrm{~mm}}\right) \times Q[\mathrm{~kW}] \\
& \times \frac{3600[\mathrm{~s} / \mathrm{h}]}{\left(A\left[\mathrm{~m}^{2}\right] \mathrm{G}\left[\mathrm{kg} / \mathrm{m}^{2} \mathrm{~h}\right]\right)} \quad \text { (middle elevation) }, \\
h_{\text {mix }}= & h_{\mathrm{in}}+\left(\frac{3177 \mathrm{~mm}}{3658 \mathrm{~mm}}\right) \times Q[\mathrm{~kW}] \\
& \times \frac{3600[\mathrm{~s} / \mathrm{h}]}{\left(A\left[\mathrm{~m}^{2}\right] G\left[\mathrm{~kg} / \mathrm{m}^{2} \mathrm{~h}\right]\right)} \quad \text { (upper elevation) } .
\end{aligned}
$$

TABLE 9: Accuracy of process parameters in void distribution measurement.

\begin{tabular}{lc}
\hline Quantity & Accuracy \\
\hline Process parameters & \\
Pressure & $1 \%$ \\
Flow & $1.5 \%$ \\
Power & $1 \%$ \\
Fluid temperature & 1 Celsius \\
Void fraction measurement & \\
CT measurement & \\
$\quad$ Gamma-ray beam width & $1 \mathrm{~mm}$ \\
$\quad$ Subchannel averaged (steady state) & $3 \%$ void \\
$\quad$ Spatial resolution of one pixel & $0.5 \mathrm{~mm}$ \\
Chordal measurement & \\
$\quad$ Gamma-ray beam width (center) & $3 \mathrm{~mm}$ \\
$\quad$ Gamma-ray beam width (side) & $2 \mathrm{~mm}$ \\
$\quad$ Subchannel averaged (steady state) & $4 \%$ void \\
Subchannel averaged (transient) & $5 \%$ void \\
\hline
\end{tabular}

Assemblies B6 and B7 utilized a cosine axial power shape. Recalling that the power shape is normalized, it is possible to determine what fraction of the total power has been imparted to the fluid between the flow inlet and the measurement sections. The mixture enthalpies for these two assemblies can be given as

$$
\begin{aligned}
h_{\text {mix }}= & h_{\mathrm{in}}+0.6598 \times \mathrm{Q}[\mathrm{kW}] \\
& \times \frac{3600[\mathrm{~s} / \mathrm{h}]}{\left(A\left[\mathrm{~m}^{2}\right] G\left[\mathrm{~kg} / \mathrm{m}^{2} \mathrm{~h}\right]\right)} \quad \text { (Lower Elevation) }, \\
h_{\text {mix }}= & h_{\mathrm{in}}+0.8172 \times \mathrm{Q}[\mathrm{kW}] \\
& \times \frac{3600[\mathrm{~s} / \mathrm{h}]}{\left(A\left[\mathrm{~m}^{2}\right] G\left[\mathrm{~kg} / \mathrm{m}^{2} \mathrm{~h}\right]\right)} \quad \text { (Middle Elevation) }, \\
h_{\text {mix }}= & h_{\mathrm{in}}+0.9353 \times \mathrm{Q}[\mathrm{kW}] \\
& \times \frac{3600[\mathrm{~s} / \mathrm{h}]}{\left(A\left[\mathrm{~m}^{2}\right] G\left[\mathrm{~kg} / \mathrm{m}^{2} \mathrm{~h}\right]\right)} \quad \text { (Upper Elevation) } .
\end{aligned}
$$


TABLE 10: Sources of error for void distribution measurement.

\begin{tabular}{|c|c|c|c|}
\hline \multirow{2}{*}{ Error source } & \multicolumn{2}{|c|}{ Chordal averaged } & \multirow{2}{*}{ CT averaged } \\
\hline & Steady state & Transient & \\
\hline \multicolumn{4}{|l|}{$\gamma$-ray measurement } \\
\hline $\begin{array}{l}\text { Effect of surrounding condition (magnetic field and temperature) } \\
\text { on measurement system }\end{array}$ & $0.1 \%$ & $0.1 \%$ & $0.1 \%$ \\
\hline Randomness of $\gamma$-ray source decay & $0.02 \%$ & $0.2 \%$ & $0.1 \%$ \\
\hline Correction error due to background & $0.0 \%$ & $0.0 \%$ & $0.0 \%$ \\
\hline Correction error due to counting loss & $<0.5 \%$ & $<0.5 \%$ & $<0.1 \%$ \\
\hline Calibration error & $0.1 \%$ & $0.1 \%$ & $0.1 \%$ \\
\hline Correction error due to attenuation by surrounding water & $0.0 \%$ & $0.0 \%$ & - \\
\hline Correction error due to scattering from multi- $\gamma$-rays & $<0.2 \%$ & $<0.2 \%$ & - \\
\hline Total & $<0.55 \%$ & $<0.6 \%$ & $<0.2 \%$ \\
\hline \multicolumn{4}{|l|}{ Subchannel density } \\
\hline Transfer to density & $<9 \mathrm{~kg} / \mathrm{m}^{3}$ & $<10 \mathrm{~kg} / \mathrm{m}^{3}$ & $<15 \mathrm{~kg} / \mathrm{m}^{3}$ \\
\hline Distribution error to subchannel & $<5 \mathrm{~kg} / \mathrm{m}^{3}$ & $<5 \mathrm{~kg} / \mathrm{m}^{3}$ & - \\
\hline Correlation error from chordal averaged to CT averaged & $<6 \mathrm{~kg} / \mathrm{m}^{3}$ & $<6 \mathrm{~kg} / \mathrm{m}^{3}$ & - \\
\hline Subchannel density & $<20 \mathrm{~kg} / \mathrm{m}^{3}$ & $<21 \mathrm{~kg} / \mathrm{m}^{3}$ & $<15 \mathrm{~kg} / \mathrm{m}^{3}$ \\
\hline Subchannel void* & 0.040 & 0.042 & 0.030 \\
\hline Uncertainty $(1 \sigma)$ & $4 \%$ & $5 \%$ & $3 \%$ \\
\hline
\end{tabular}

${ }^{*}$ Reference averaged density is $500 \mathrm{~kg} / \mathrm{m}^{3}$.

TABLE 11: Number of gamma-ray beams.

\begin{tabular}{|c|c|c|}
\hline Test assembly & CT measurement & $\begin{array}{c}\text { Chordal } \\
\text { measurement }\end{array}$ \\
\hline Subchannel & $\begin{array}{c}2 \\
(X \text { and } Y \text { direction })\end{array}$ & $\begin{array}{c}2 \\
(X \text { and } Y \text { direction })\end{array}$ \\
\hline Rod bundle & 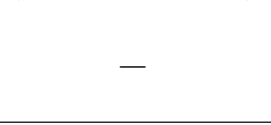 & $\begin{array}{c}6 \text { beams } \times 2 \times 3 \\
\text { section } \\
\text { (total } 36 \text { beams) }\end{array}$ \\
\hline
\end{tabular}

TABLE 12: Time required to perform void fraction measurements.

\begin{tabular}{lcc}
\hline Item & $\begin{array}{c}\mathrm{CT} \\
\text { measurement }\end{array}$ & $\begin{array}{c}\text { Chordal } \\
\text { measurement }\end{array}$ \\
\hline Steady state & & \\
Time needed & $\begin{array}{c}5 \mathrm{~s} / \mathrm{step}^{\mathrm{R}} \times{ }^{\mathrm{T}} 33 \\
(\text { it takes } 2 \mathrm{~h})\end{array}$ & $\begin{array}{c}100 \mathrm{~s} \\
\text { sampling cycle } 0.1 \mathrm{~s}\end{array}$ \\
Measurement & 2 times & 3 times \\
\hline Transient & - & $200 \mathrm{~s}$ \\
Time needed & - & 1 time \\
Measurement & &
\end{tabular}

After applying these equations and calculating the qualities for each case, the following results were obtained. Figures $17,18,19$, and 20 show the deviation of experimental quality from recalculated quality for test series 5, 6, 7, and 8 (resp.).
TABLE 13: Accuracy of process parameters in DNB measurement.

\begin{tabular}{lc}
\hline Quantity & Accuracy \\
\hline Process parameters & \\
Pressure & $1 \%$ \\
Flow & $1.5 \%$ \\
Power & $1 \%$ \\
Fluid temperature & 1 Celsius \\
\hline
\end{tabular}

\section{Selected Examples of Comparative Analysis of Participant Results}

Detailed comparative analysis of submitted participants' results for different exercises of the two phases of the benchmark has been reported in $[5,6]$. In this paper, selected examples are shown to illustrate the methodology of comparisons and indicate the observed tendencies.

3.1. Phase I-Void Distribution. There were a total of twenty (20) participants for exercise 1 of phase I-Steady-state single subchannel benchmark [5]. Sixteen (16) of these participants submitted void fraction results, and eight (8) submitted axial void distribution results. Table 14 lists these participants as well as the codes for which results were submitted.

The axial nodalization of the problem varied widely depending on the code type. CFD codes, as expected, had significantly more nodes than the system and subchannel codes: both NEPTUNE [7] and ANSYS (ANSYS) [8] used nodalizations of $\sim 100,000-1,000,000$ nodes, while both KTH and PSI used about 30 axial nodes for TRACE. CATHARE 
Subchannel test

CT measurement

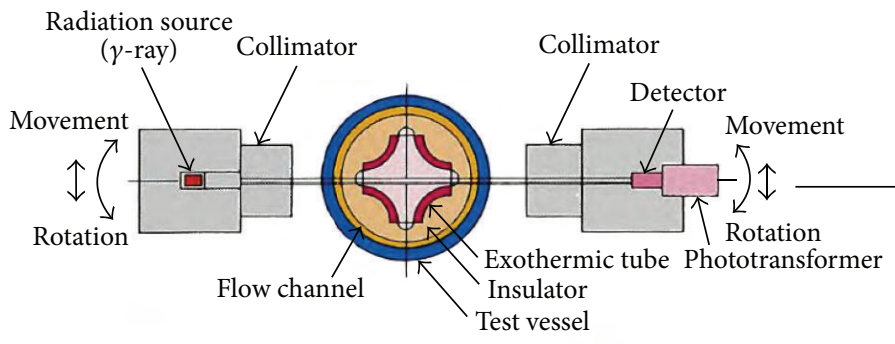

Chordal measurement
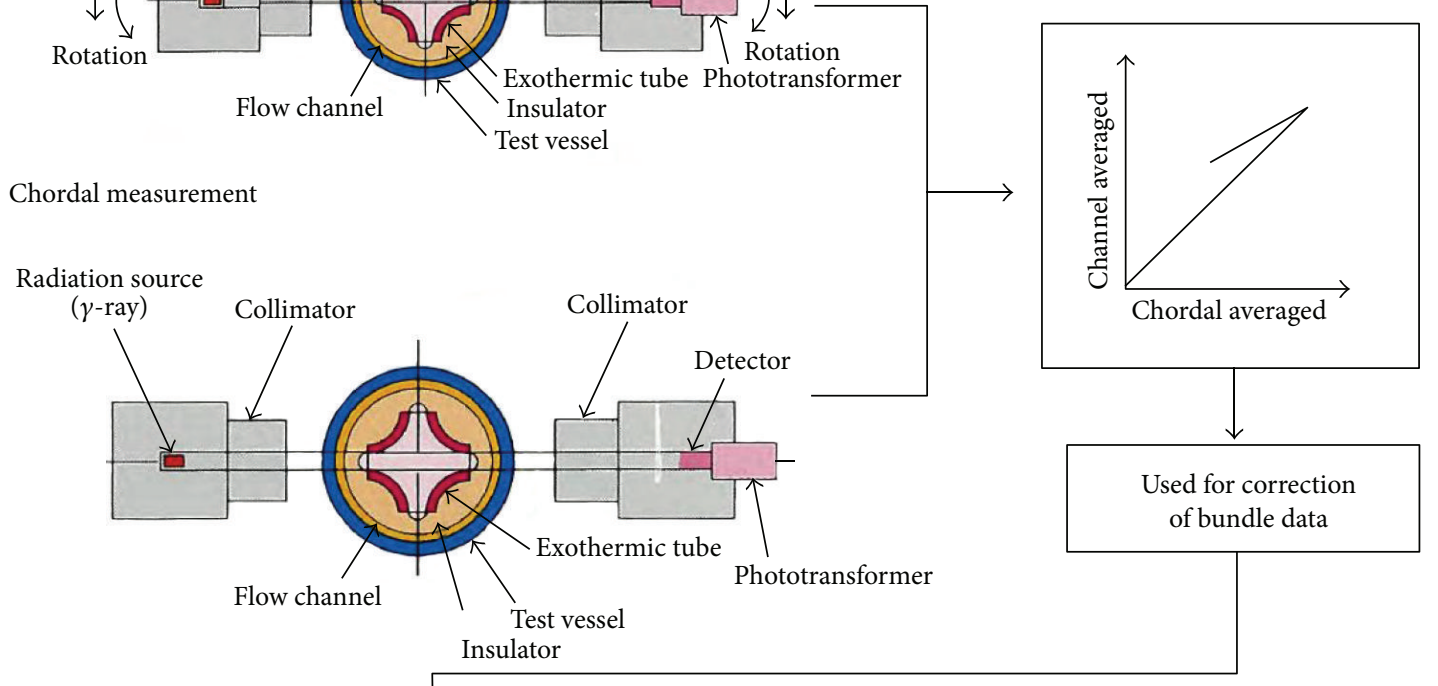

Bundle test
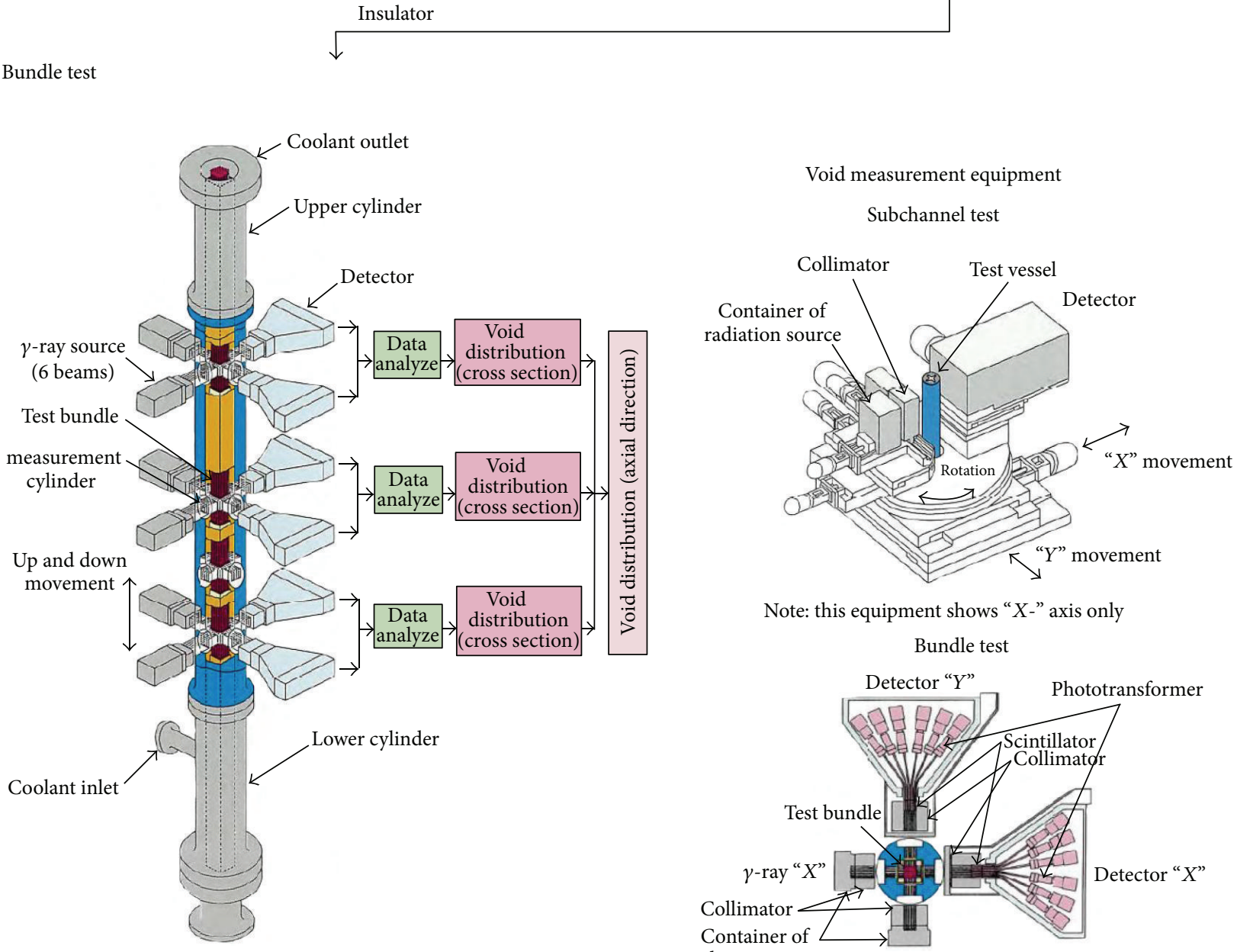

Note: this equipment shows " $X$-" axis only

Bundle test

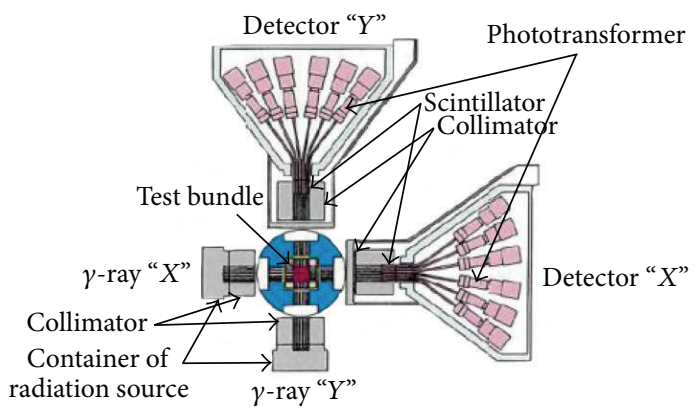

Figure 11: Void fraction measurement procedure. 


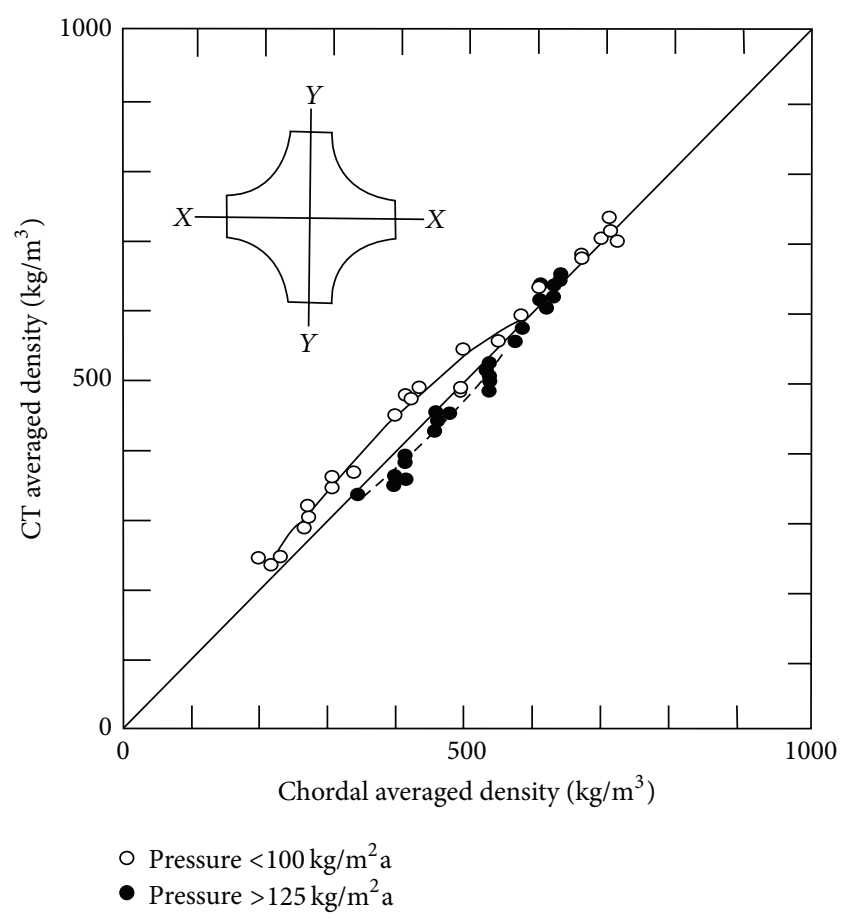

Figure 12: Relation Between Chordal and CT Averaged Densities (for S1).

TABLE 14: Phase I, exercise 1 participants and code list.

\begin{tabular}{lcc}
\hline Participant & Code & Code type \\
\hline ANL & STAR-CD & CFD \\
ANSYS & ANSYS & CFD \\
EDF & NEPTUNE & CFD \\
GRS & ANSYS-CFX & CFD \\
HZDR & ANSYS-CFX & CFD \\
PSI & STAR-CD & CFD \\
EDF & THYC & Porous media \\
AREVA & F-COBRA-TF & Subchannel \\
CEA-Saclay & FLICA-OVAP & Subchannel \\
CSA & VIPRE & Subchannel \\
JNES & CHAMP-ITA & Subchannel \\
KAERI & MATRA & Subchannel \\
KIT & SUBCHANFLOW & Subchannel \\
McMaster & ASSERT-PV & Subchannel \\
PSI & FLICA & Subchannel \\
CEA-Grenoble & CATHARE 3 & System \\
IRSN & CATHARE 2 & System \\
KTH & TRACE & System \\
PSI & TRACE & System \\
UNIPI & CATHARE 2 & System \\
\hline
\end{tabular}

2 (UNIPI) [9] and STAR-CD (PSI) both used approximately 100 axial nodes.
TABle 15: Phase I, exercise 2 participants and code list.

\begin{tabular}{lcc}
\hline Participant & Code & Code type \\
\hline EDF & THYC & Porous media \\
AREVA & F-COBRA-TF & Subchannel \\
CEA-Saclay & FLICA-OVAP & Subchannel \\
CSA & VIPRE & Subchannel \\
JNES & CHAMP-ITA & Subchannel \\
KAERI & MATRA & Subchannel \\
KIT & SUBCHANFLOW & Subchannel \\
McMaster & ASSERT-PV & Subchannel \\
NRI & VIPRE & Subchannel \\
PSI & FLICA & Subchannel \\
WEC/INVAP & VIPRE & Subchannel \\
CEA-Grenoble & CATHARE 3 & System \\
Chalmers & RELAP-5 & System \\
KTH & TRACE & System \\
PSI & TRACE & System \\
UNIPI & CATHARE 2 & System \\
USNRC & TRACE & System \\
\hline
\end{tabular}

TABle 16: Phase II, exercise 2 participants.

\begin{tabular}{lcc}
\hline Participant & Code & Code type \\
\hline EDF & THYC & Porous media \\
CEA-Saclay & FLICA-OVAP & Subchannel \\
KAERI & MATRA & Subchannel \\
KIT & SUBCHANFLOW & Subchannel \\
McMaster & ASSERT-PV & Subchannel \\
PSI & FLICA & Subchannel \\
NRI & VIPRE & Subchannel \\
CEA-Grenoble & CATHARE 3 & System \\
KTH & TRACE & System \\
\hline
\end{tabular}

TABLE 17: Phase II, exercise 3 participants.

\begin{tabular}{lcc}
\hline Participant & Code & Code type \\
\hline EDF & THYC & Porous media \\
CEA-Saclay & FLICA-OVAP & Subchannel \\
KAERI & MATRA & Subchannel \\
KIT & SUBCHANFLOW & Subchannel \\
McMaster & ASSERT-PV & Subchannel \\
PSI & FLICA & Subchannel \\
NRI & VIPRE & Subchannel \\
KTH & TRACE & System \\
\hline
\end{tabular}

Finally, a variety of wall drag and heat transfer coefficients were also used. THYC, for example, used Gautier for monophasic and Chen for diphasic heat transfer, while FLICA (PSI) [10] used the Blasius correlation for single-phase friction losses with the Friedel correlation as a two-phase 


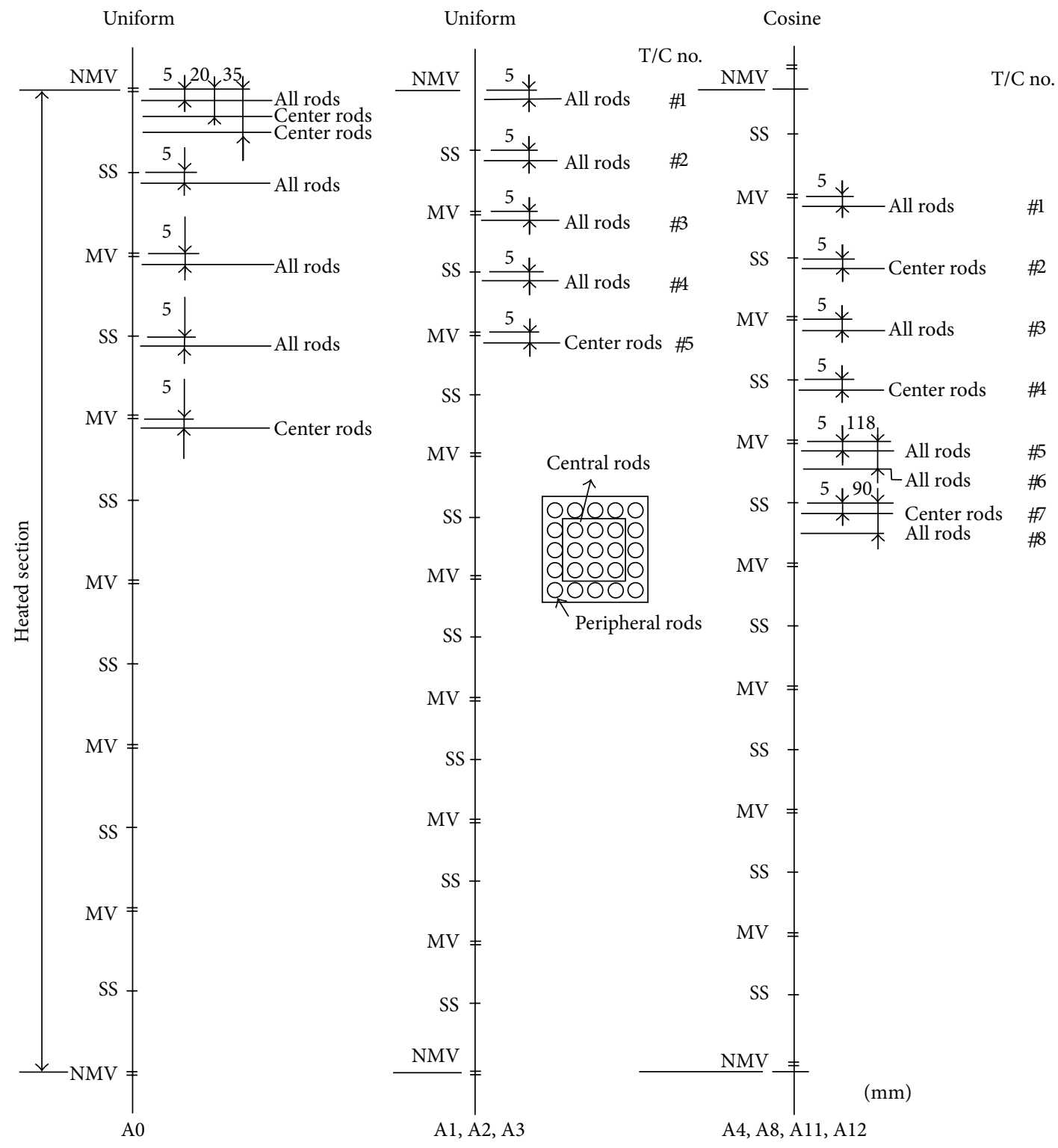

FIGURE 13: Locations of thermocouples for test assemblies.

multiplier. A number of codes used Dittus-Boelter for singlephase heat transfer and a variety of correlations (Jens-Lottes for FLICA (PSI)) were used.

Statistical methodology has been utilized for comparative analysis. Mean error and standard deviation were calculated for each code for each test series. The mean error (where $N$ is the total number of test cases) was represented as $\bar{\alpha}=$ $\sum_{n=1}^{N} \alpha^{n} / N$, where the void fraction error for test case " $n$ " is represented as $\alpha^{n}=\left(\alpha_{\text {code }}^{n}-\alpha_{\text {exp }}^{n}\right)$.

The standard deviation was given as $\sigma=$
$\pm \sqrt{\sum_{n=1}^{N}\left(\alpha^{n}-\bar{\alpha}\right)^{2} /(N-1)}$.

Figure 21 summarizes the mean error of participant void fraction calculations as compared to measurements, while Figure 22 summarizes the standard deviation of those results.

There was no clear bias in the calculation of void fraction for any of the four subchannels. Although some of the codes consistently predicted the correct thermal equilibrium quality, there was a tendency to overpredict it at the low elevation and underpredict it at the high elevation.

There were a total of seventeen (17) participants for exercise 2 of phase I-steady-state bundle benchmark [5]. All sixteen submitted void fraction results, while two submitted axial void distribution results. Table 15 lists these participants as well as the codes for which results were submitted.

Some modeling considerations specific to this exercise include increasing the number of axial nodes and modeling spacer grids. A number of the codes (such as THYC) did not model spacer grid effects, while others (CATHARE 3 (CEAGrenoble) [11]) applied a pressure loss one cell in front of the spacer grid. A number of cross-flow models were also used. THYC used Chexal-Lellouche for drift flux as well as a no-slip condition and Cheng-Todreas for turbulent diffusivity, while CATHARE 3 (CEA-Grenoble) used a turbulent dispersion 


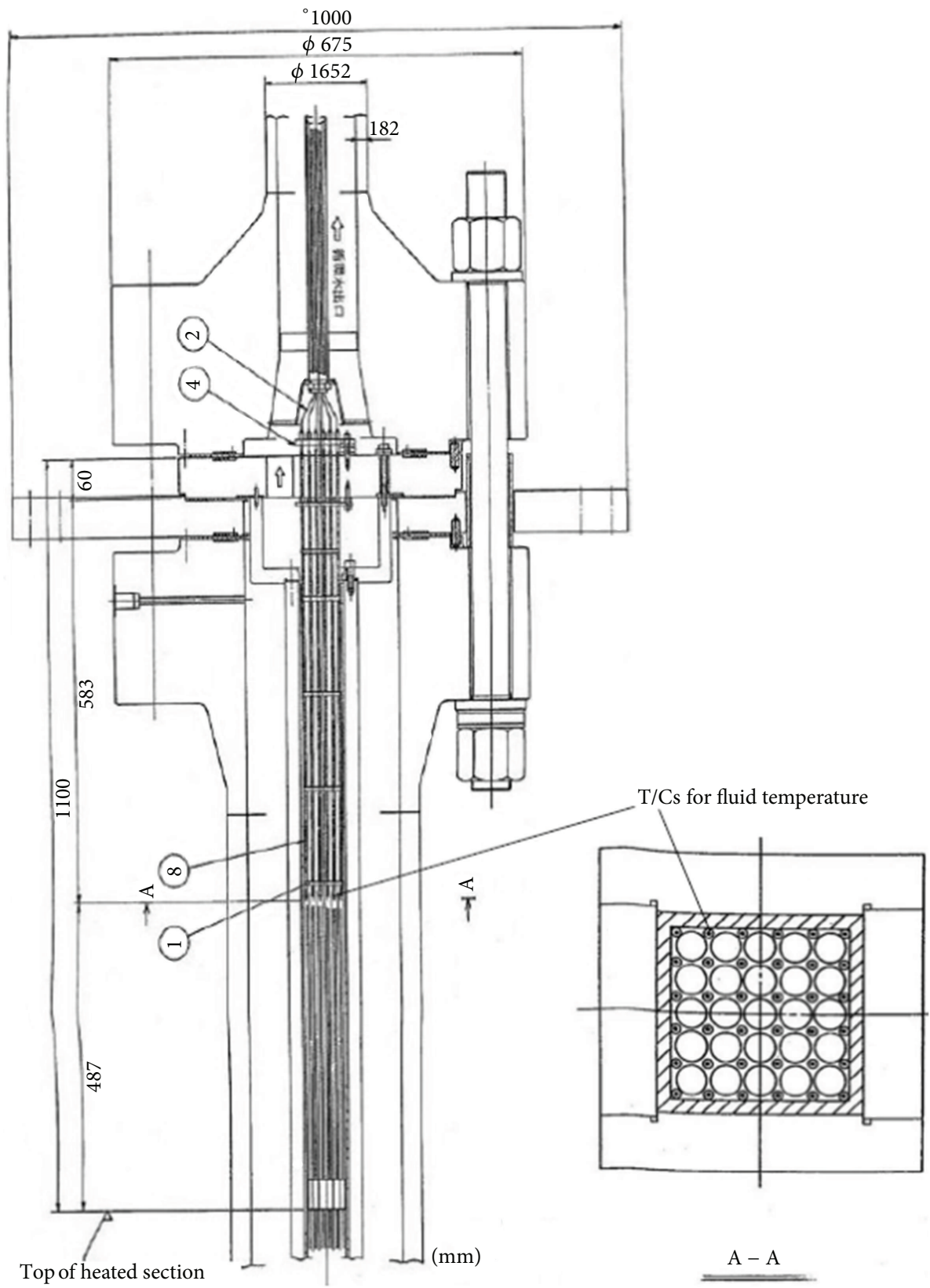

FIGURE 14: Diagram of fluid temperature measurement setup.

term. Yet, other codes did not consider cross-flow effects. Statistical methodology also was utilized to calculate the mean error and standard deviation for each measurement location for each test series. Figures 23, 25, 27, and 29 summarize the error of participants' void fraction predictions, while Figures $24,26,28$, and 30 summarize the standard deviation of these results.

It was noted that the codes consistently overpredicted the void fraction at the lower elevation in the bundle. However, the results were generally improved at higher elevations, although some underprediction could be seen. Both of these observations are clearly represented in the plots of mean error for each test series.

The majority of the codes also consistently predicted the correct thermal equilibrium quality at the lower elevations, with the only exceptions being KTH's TRACE and UNIPI's CATHARE, which overpredicted the quality. All of the codes tended to underpredict the quality at the upper bundle elevations.

3.2. Phase II-Departure of Nucleate Boiling. The list of the participants as well as the codes for which results were 


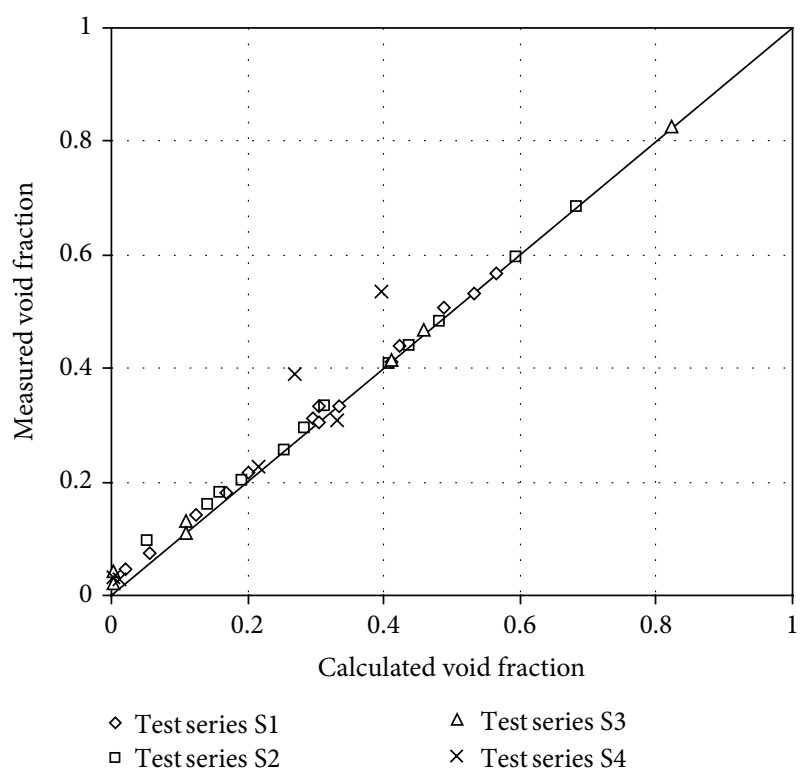

FIGURE 15: Deviation of measured void fraction from recalculated void fraction.

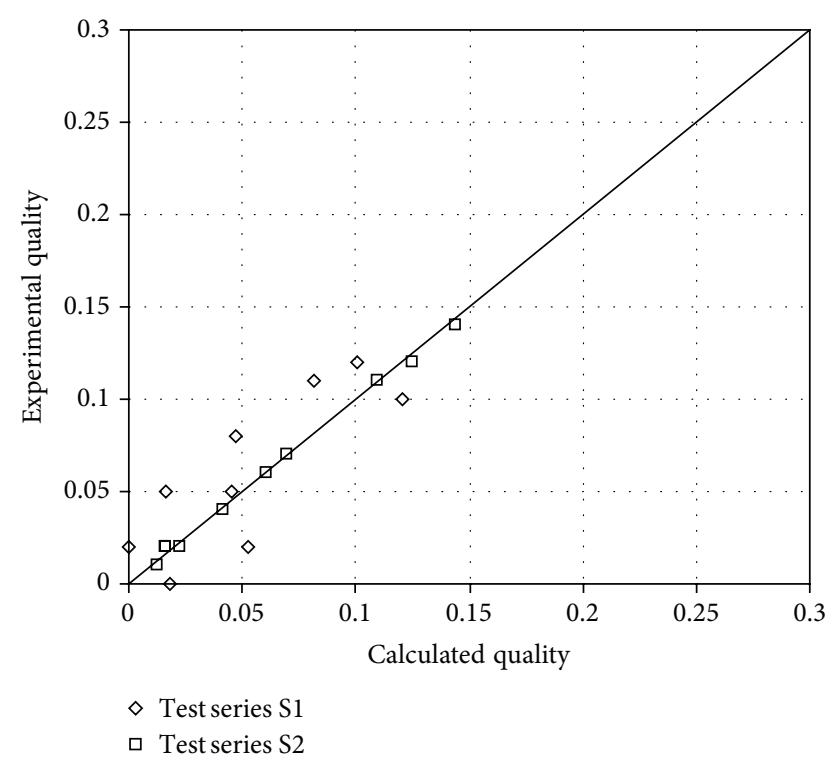

FIGURE 16: Deviation of measured quality from recalculated quality for test series 1 and 2 .

submitted for exercise 2 of phase II (steady-state DNB) benchmark is shown in Table 16.

The codes used in this exercise varied widely in the DNB modeling approach used. ASSERT-PV, TRACE (KTH), CATHARE 3, and FLICA (PSI) all used Groeneveld lookup tables, while MATRA used the EPRI CHF correlation and FLICA-OVAP [12] used the Shah correlation.

Figure 31 shows the mean error of each code for DNB power for each test series. Figure 32 shows the standard deviation of each code for DNB power for each test series.

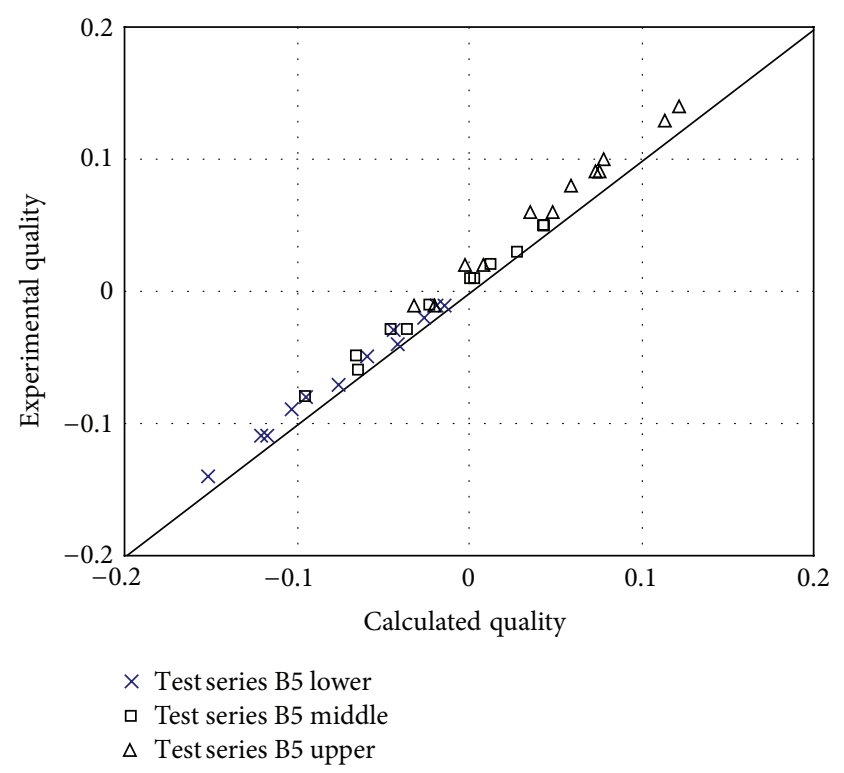

FIGURE 17: Deviation of measured quality from recalculated quality for test series 5 .

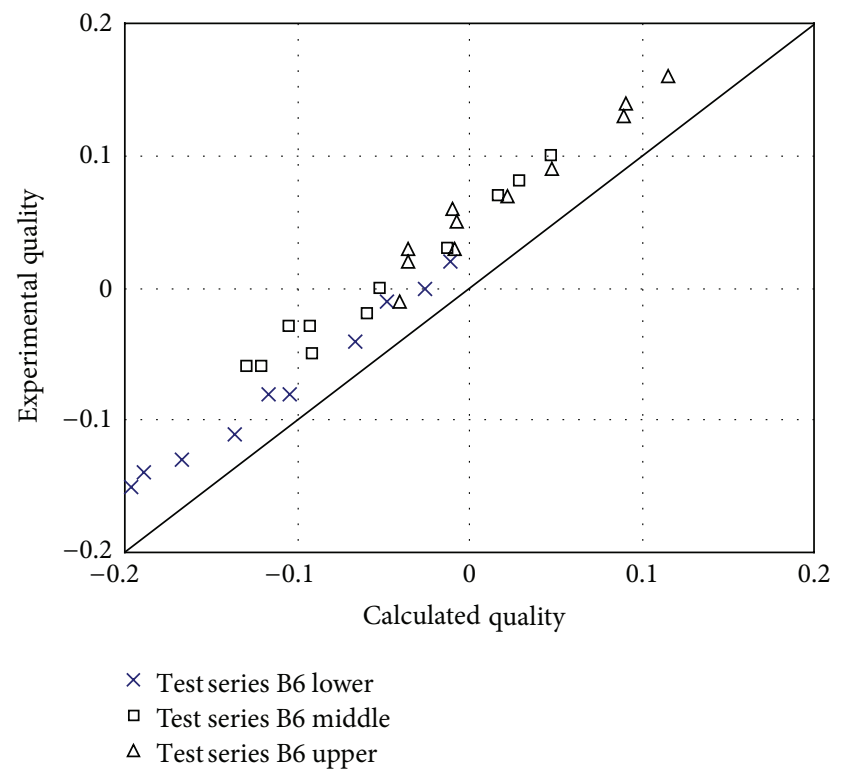

FIGURE 18: Deviation of measured quality from recalculated quality for test series 6 .

The codes were generally able to calculate the DNB power satisfactorily, and there was no observable bias across test series. The DNB power was consistently overpredicted in Test series 0 , while it was underpredicted in test series $2,3,4$, and 13. There was also considerable variation in the predictions of axial elevation of first detected DNB. It should be noted that the measured data represents the first thermocouple at which DNB was detected. Therefore, it is the latest (axially speaking) that the onset of DNB would have occurred and is not an exact value as DNB could have occurred lower on the bundle. 


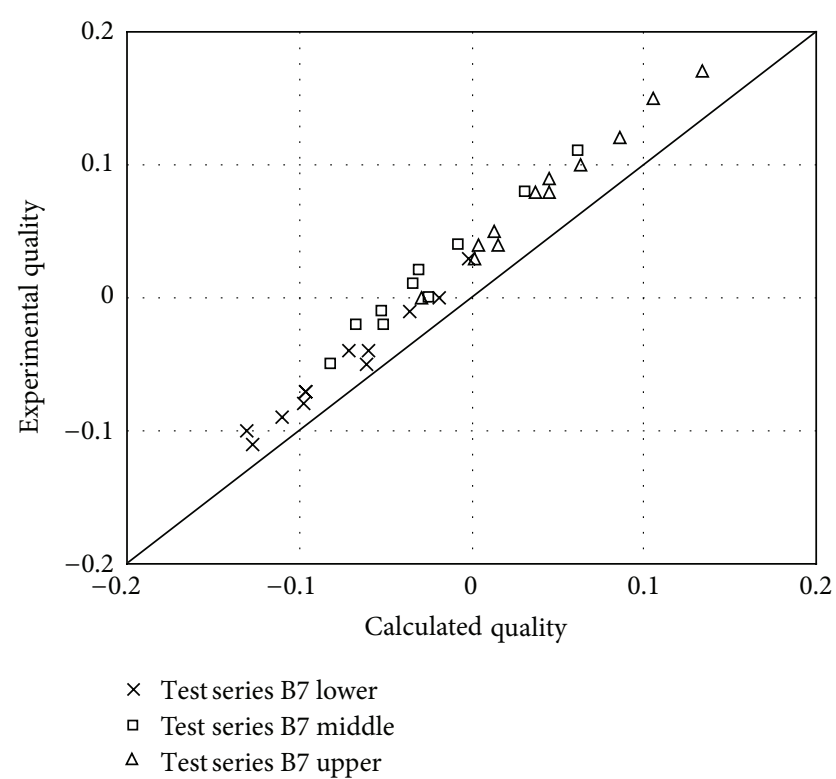

FIGURE 19: Deviation of measured quality from recalculated quality for test series 7 .

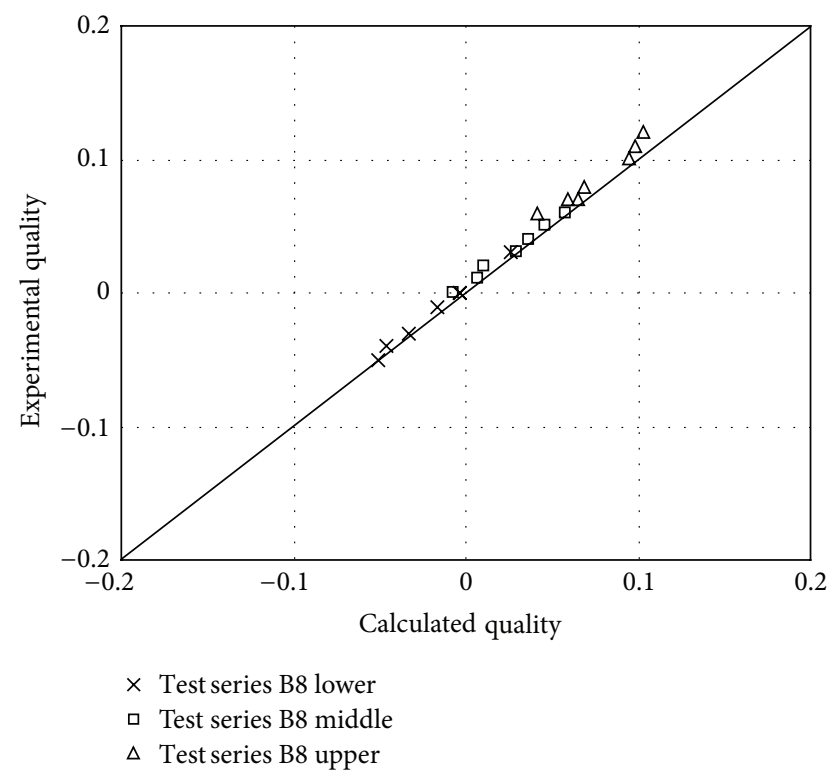

FIGURE 20: Deviation of measured quality from recalculated quality for test series 8 .

There were a total of eight (8) participants for exercise 3 of phase II-transient DNB benchmark [6]. Table 17 lists these participants as well as the codes for which results were submitted.

The same statistical methodology was utilized also for these comparisons. The mean error and standard deviation were calculated for each measurement location for each test series. Figure 33 shows the mean error of each code for time of the detected DNB for each test series. Figure 34 shows the mean error of each code for DNB power for each test series.

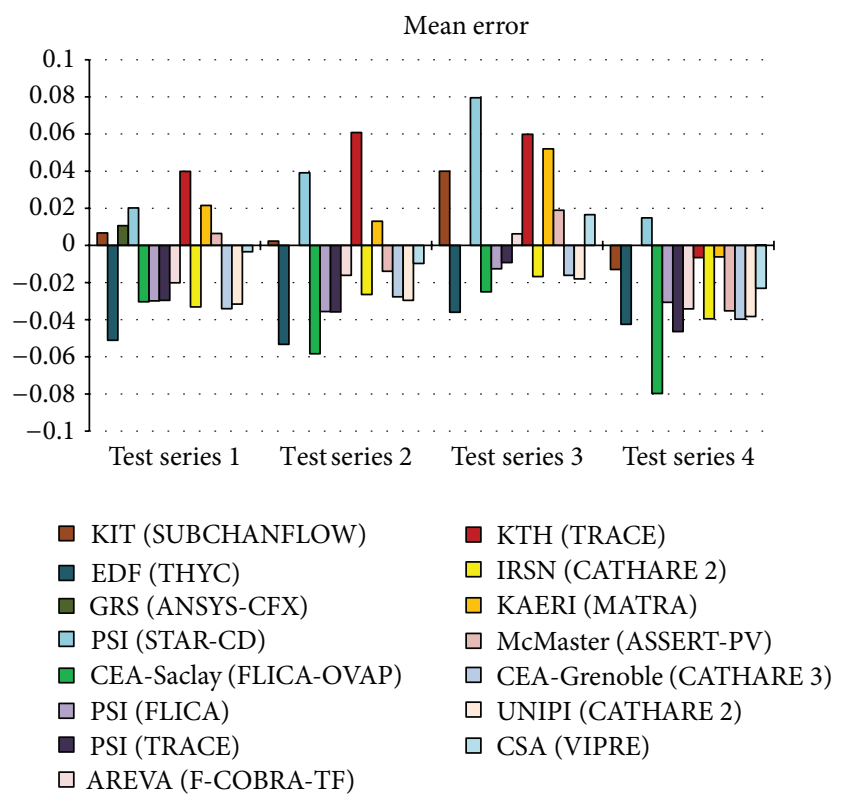

FIGURE 21: Void fraction mean error by test series.

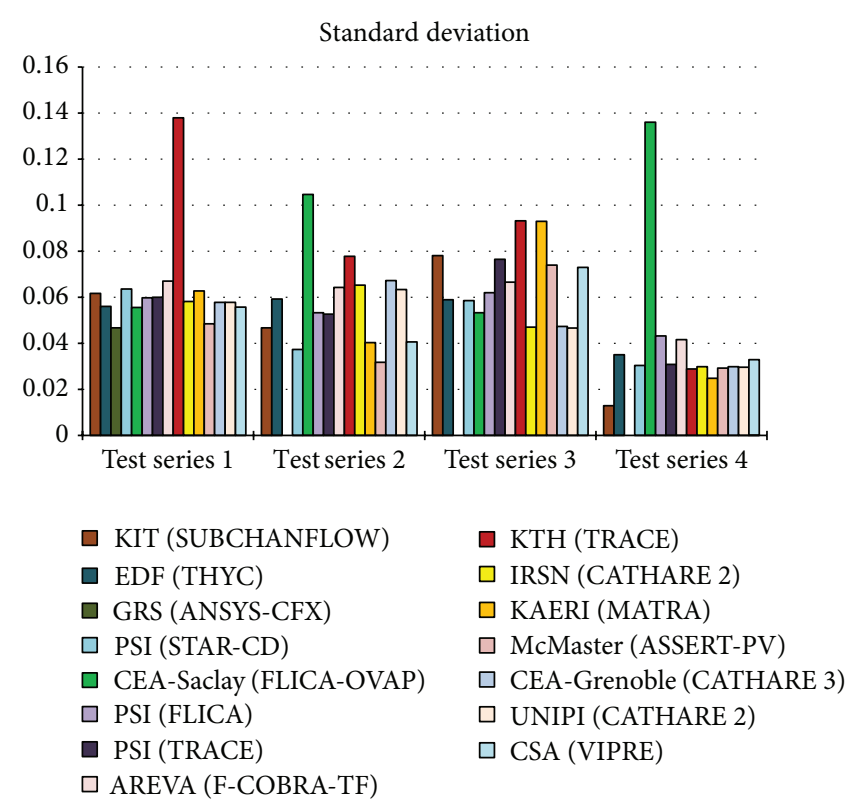

Figure 22: Void fraction standard deviation by test series.

In general, codes were not able to predict the time of DNB during the simulated transients. Most of the codes calculate earlier DNB occurrence for both bundle types (with, test series 11, and without, test series 12, thimble rod in the central region). THYC always predicts later DNB. FLICA-OVAP and SUBCHANFLOW [13] predictions show dependence on the radial power shape for both DNB power and DNB time. MATRA [14] seems to give reasonable predictions of the DNB time but significantly overpredicts the DNB power. 

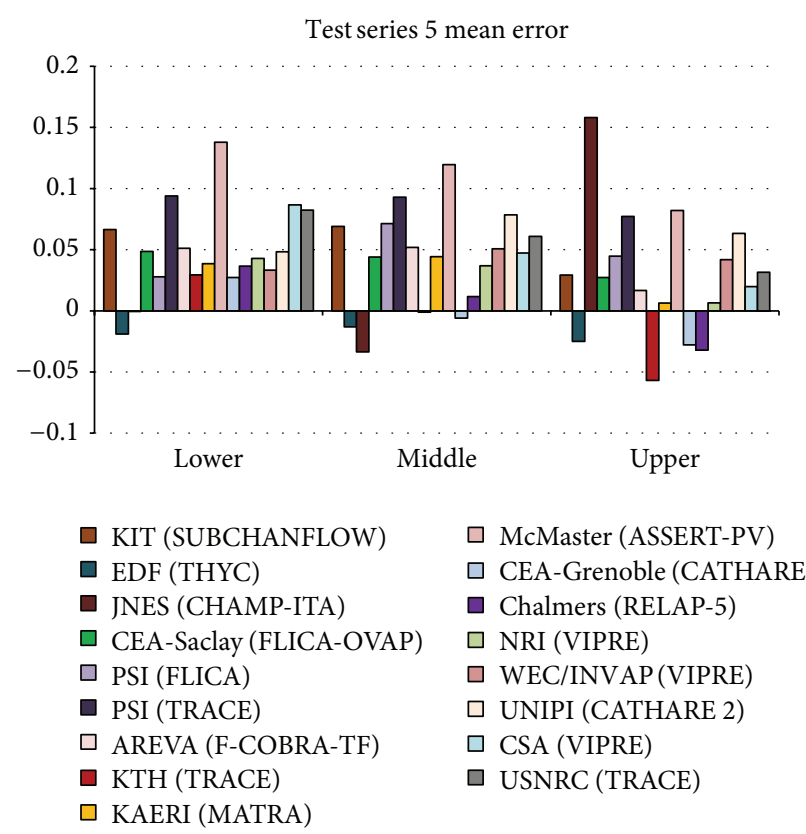

$\square$ McMaster (ASSERT-PV)

$\square$ CEA-Grenoble (CATHARE 3)

$\square$ Chalmers (RELAP-5)

$\square$ NRI (VIPRE)

$\square$ WEC/INVAP(VIPRE)

$\square$ UNIPI (CATHARE 2)

$\square$ CSA (VIPRE)

$\square$ USNRC (TRACE)

Figure 23: Test series 5 void fraction mean error.

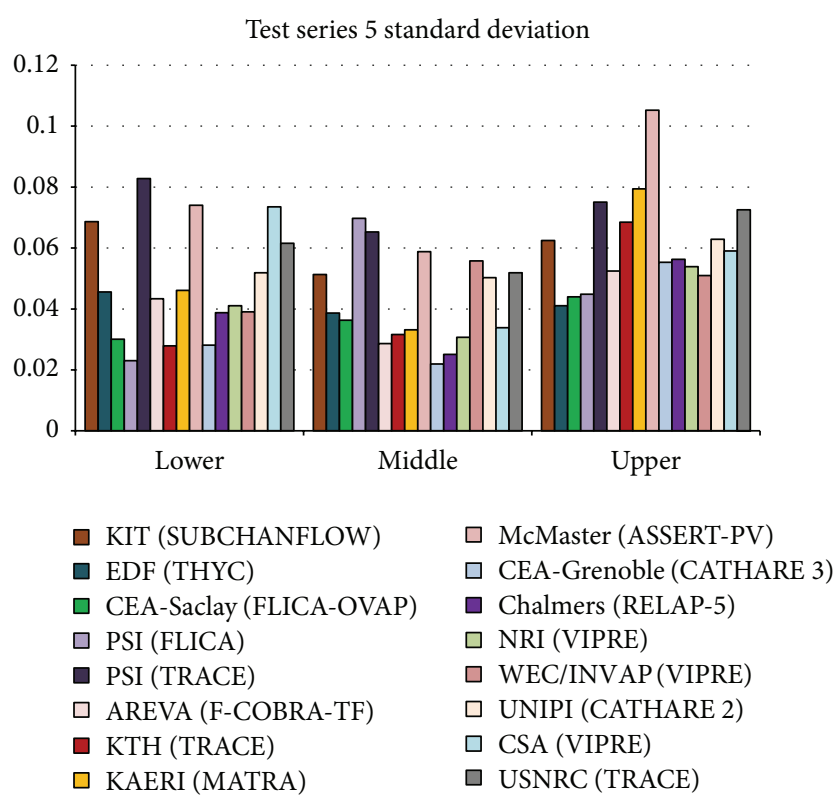

FIGURE 24: Test series 5 void fraction standard deviation.

\section{Conclusions}

The OECD/NRC PSBT benchmark was designed to provide a set of data for the development and validation of the next generation of thermal-hydraulic codes. It consisted of two phases: a void fraction benchmark and a departure from nucleate boiling benchmark. Data regarding the test sections and conditions was provided to participants for use in calculations. The code results from all participants were then compiled and analyzed. In the development of the benchmark specification, a number of support studies

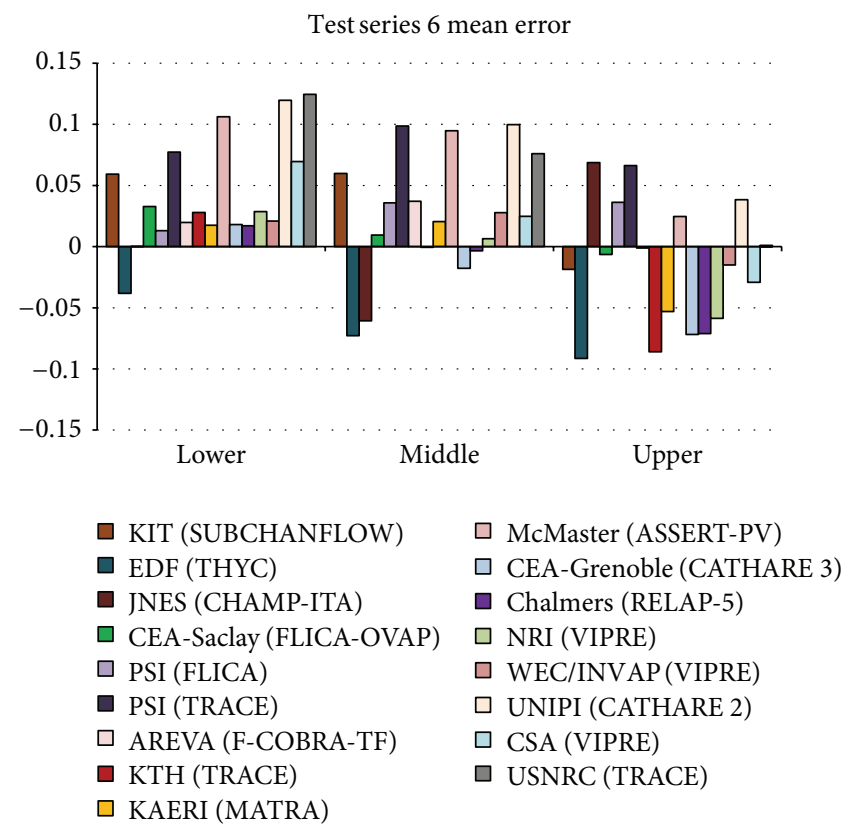

Figure 25: Test series 6 void fraction mean error.

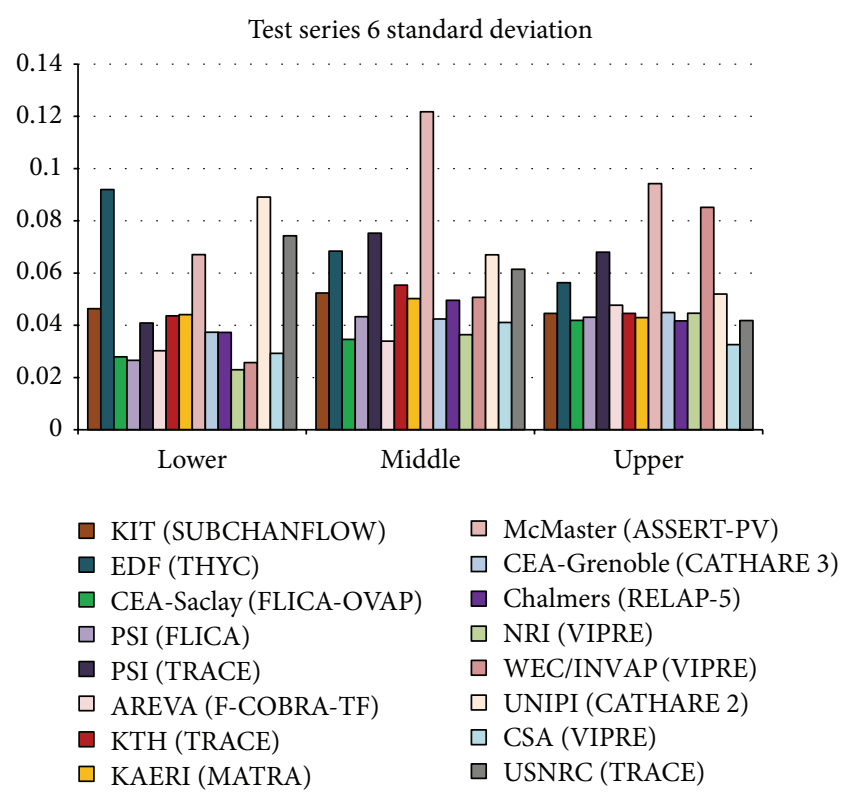

Figure 26: Test series 6 void fraction standard deviation.

were performed. The experimental void fraction and quality were recalculated using the experimentally determined fluid density for each of the benchmark test cases, and a deviation between these recalculated values and the measured values was observed. Studies were also conducted to determine the effect of the downcomer region on the fluid temperature and the effect of the CT mask on void fraction at subcooled boiling conditions. The participants' results for each benchmark exercise were analyzed, and conclusions were drawn. In the results for the first phase, it was observed that the codes tended to overpredict the thermal equilibrium quality at 


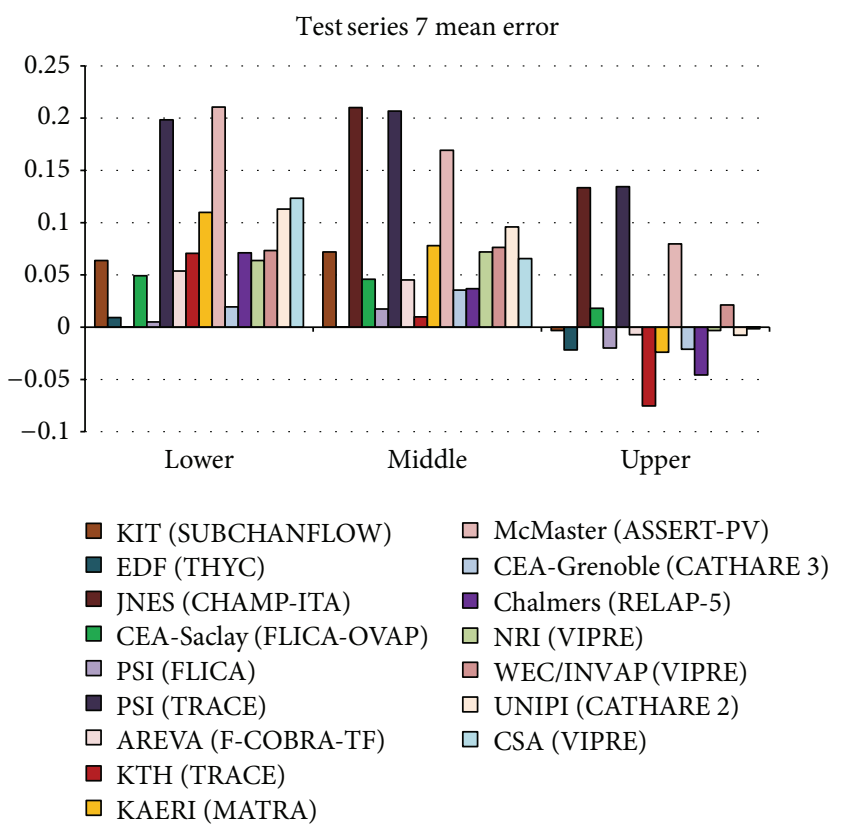

FIGURE 27: Test series 7 void fraction mean error.

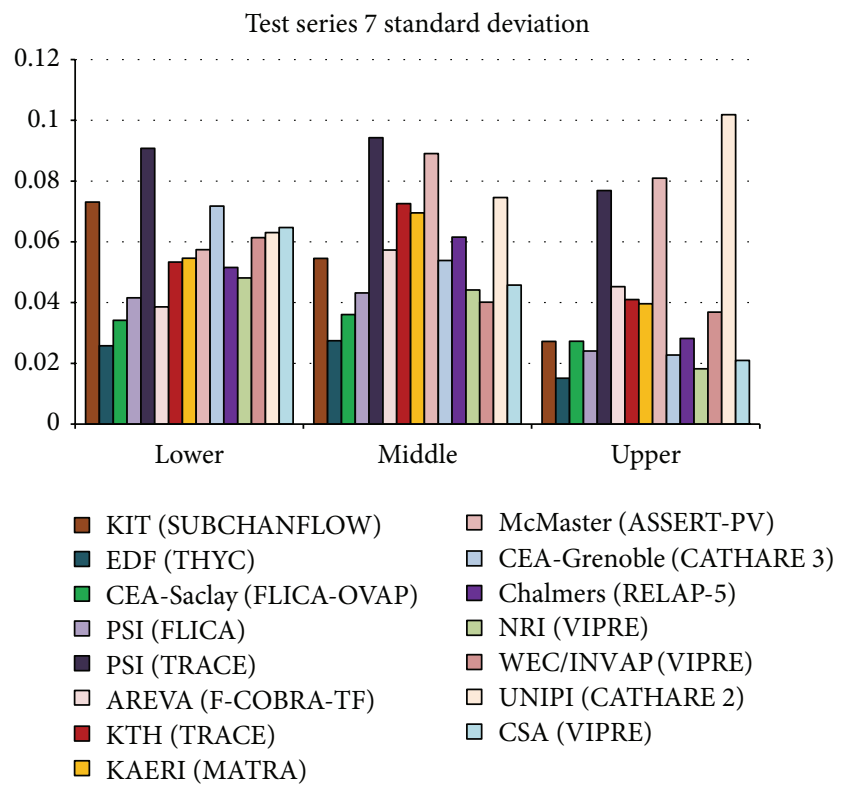

Figure 28: Test series 7 void fraction standard deviation.

lower elevations and underpredict it at higher elevations. There was also a tendency to overpredict void fraction at lower elevations and underpredict it at high elevations for the bundle test cases. The overprediction of void fraction at low elevations is likely caused by the $\mathrm{X}$-ray densitometer measurement method used. Under subcooled boiling conditions, the voids accumulate at heated surfaces (and are therefore not seen in the center of the subchannel, where the measurements are being taken), so the experimentally determined void fractions will be lower than the actual void fraction. The underprediction of void fraction at high

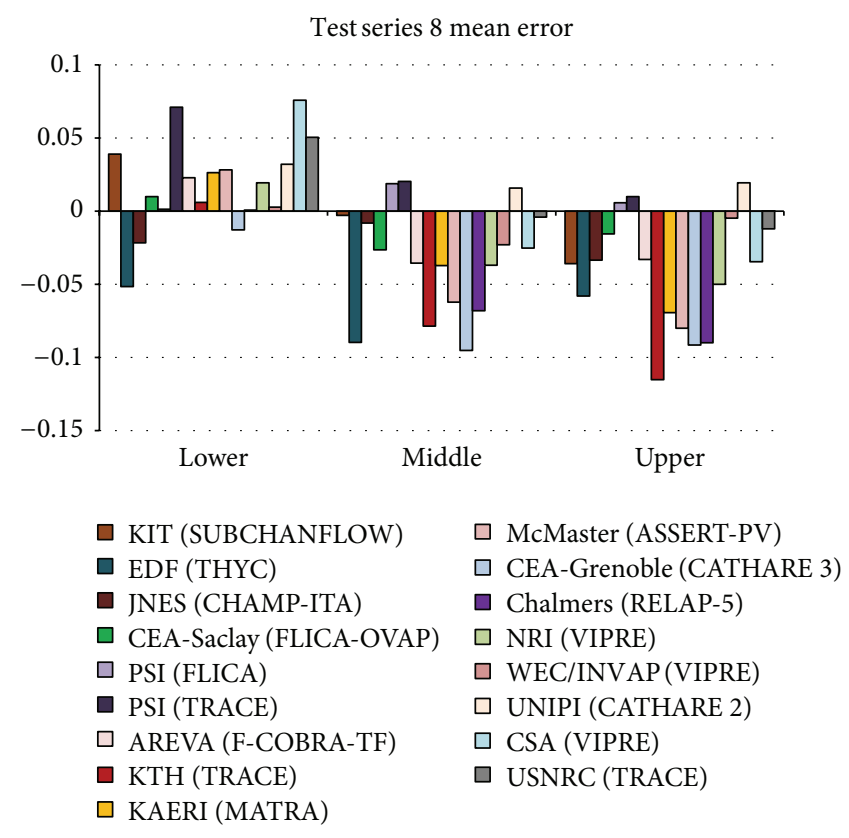

FIGURE 29: Test series 8 void fraction mean error.

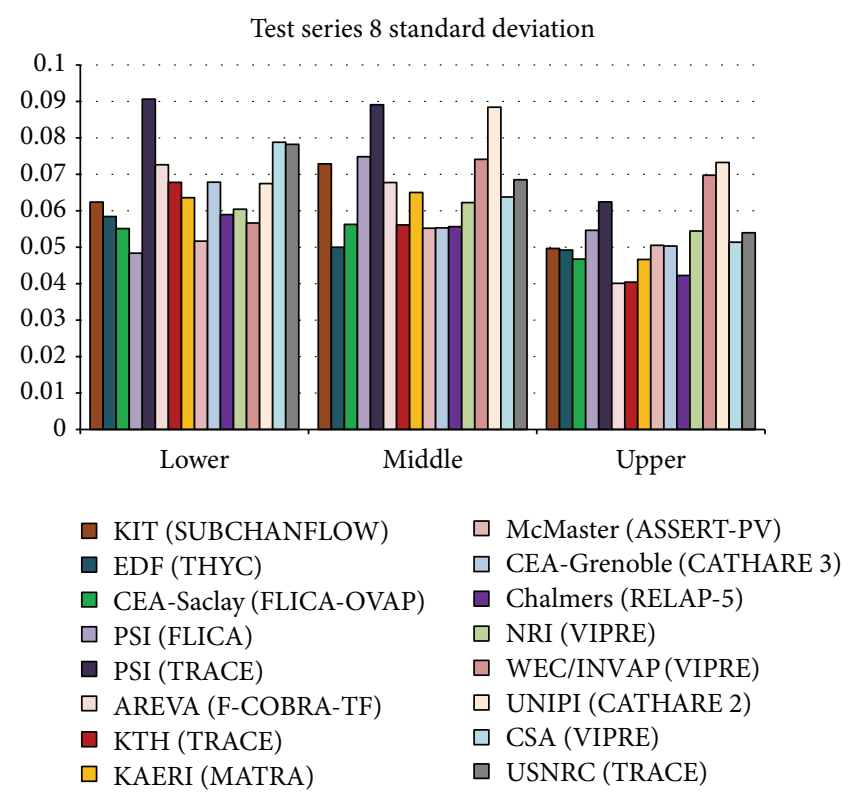

FIGURE 30: Test series 8 void fraction standard deviation.

elevations is smaller as compared to overprediction at low elevations, and the code results were generally improved at higher elevations. Some of the best results were achieved by codes that used either turbulent mixing or dispersion terms for modeling cross-flow. It was also noted that, for the bundle cases, some of the codes were not correctly calculating the bundle-averaged thermal equilibrium quality, and this may indicate an inability to predict the correct void fraction. A time shift was noted in the void fraction results for the temperature increase transient cases, indicating that the test apparatus may have experienced unexpected heat transfer 


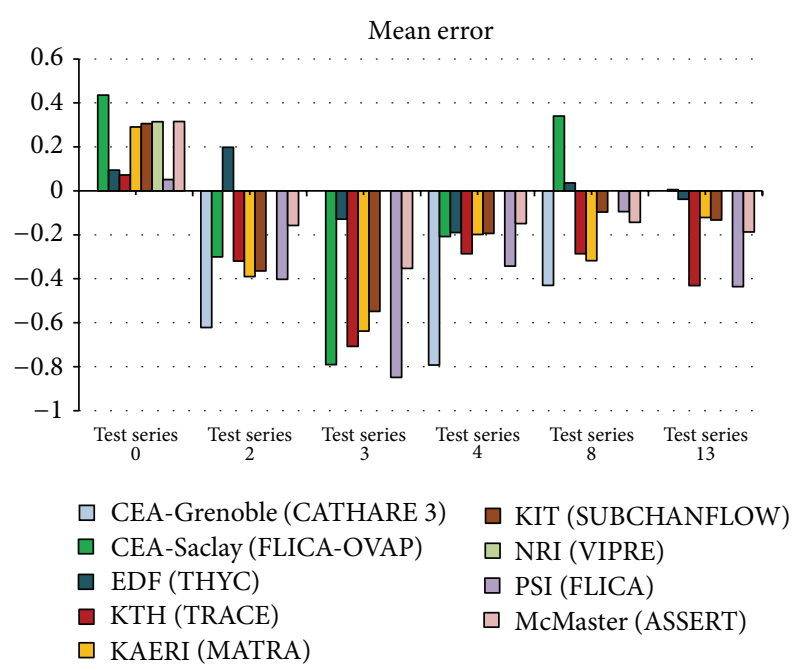

FIgURE 31: Mean error of predicted DNB power.

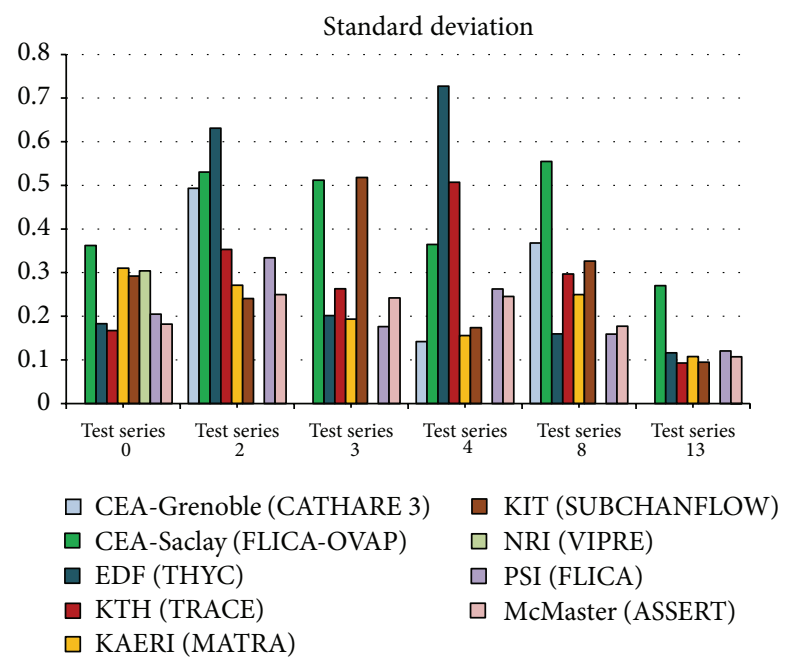

FIGURE 32: Standard deviation of predicted DNB power.

between the downcomer and test section. This heat transfer is only expected to be of significance in the transient test cases as the steady-state cases allow the system to reach thermal equilibrium.

The participants' results for each benchmark exercise of phase II were analyzed, and conclusions were drawn. Based on the final results for the second phase, a number of conclusions were drawn. The codes were generally able to replicate the results of the mixing test, staying within $5 \%$ of the experimental fluid exit temperature. THYC showed the largest errors, while all codes had difficulty with the test case $01-1237$. The uncertainty related to the spacer grid orientation in the mixing tests may explain the asymmetries seen in the experimental data, but no sensitivity study was performed to determine the exact effect on the flow, so this uncertainty cannot be quantified. The improvement between FLICA-OVAP and FLICA was noticeable, with the main difference between the two codes being that FLICA-OVAP

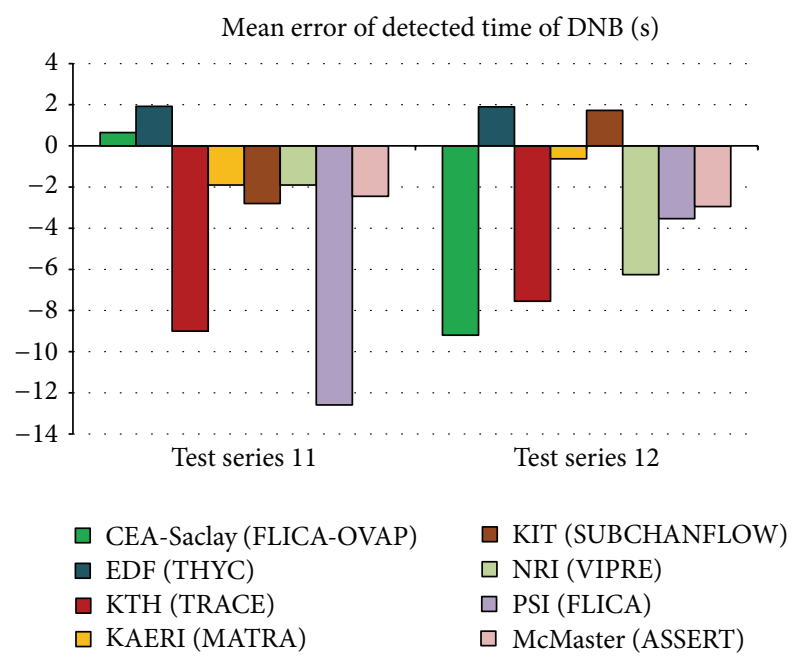

Figure 33: Mean error of detected time of DNB.

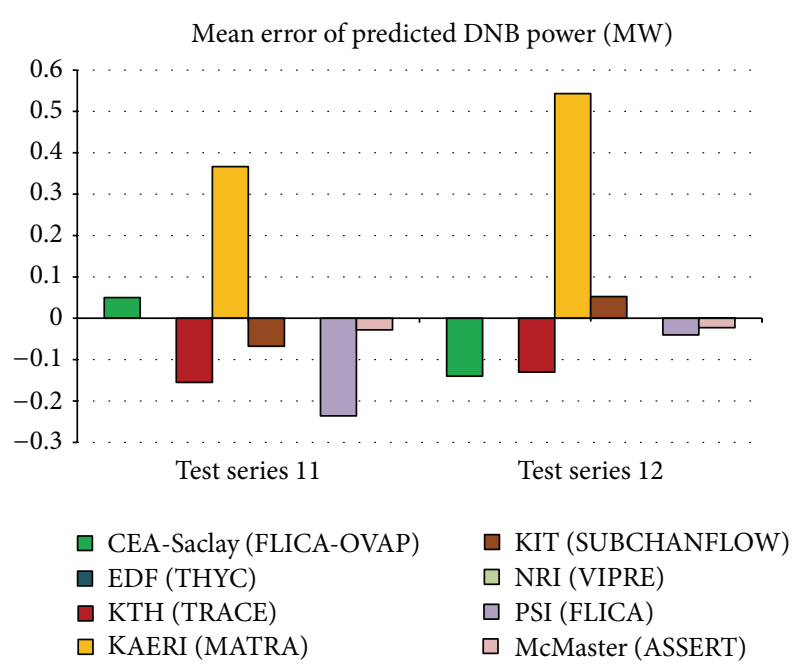

Figure 34: Mean error of predicted DNB power.

implicitly assigned flow regime based on drift flux, while FLICA assumes single phase flows. In exercises 2 and 3, the codes were generally able to predict the DNB power as well as the axial location of the onset of DNB (for the steadystate cases) and the time of DNB (for the transient cases). It was noted that the codes that used the EPRI CHF correlation (such as MATRA and SUBCHANFLOW) had the lowest mean error in exercise 2 for predicted DNB power.

\section{Acknowledgments}

The authors would like to acknowledge the help of Alexander Velazquez-Lozada and Stephen Bajorek from the US Nuclear Regulatory Commission. The OECD/NRC PSBT benchmark is financially supported by the US NRC under a cooperative agreement grant. 


\section{References}

[1] Proving Test on the Reliability for Nuclear Fuel Assemblies, Summary Report of Proving Tests on the Reliability for Nuclear Power Plant-1989, Nuclear Power Engineering Test Center, 1989.

[2] K. Hori, K. Miyazaki, T. Kurosu, S. Sugiyama, J. Matsumoto, and Y. Akiyama, "In bundle void fraction measurement of PWR fuel assembly," in Proceedings of the 2nd International Conference on Nuclear Engineering (ICONE-2), vol. 1, pp. 69-76, San Francisco, Calif, USA, March 1993.

[3] Pamphlet of Takasago Engineering Laboratory, Nuclear Power Engineering Center (NUPEC).

[4] A. Rubin, A. Schoedel, and M. Avramova, "OECD/NRC Benchmark Based on NUPEC PWR Subchannel and Bundle Tests (PSBT). Volume I: Experimental Database and Final Problem Specifications," NEA/NSC/DOC(2010)1, January 2010.

[5] A. Rubin and M. Avramova, "OECD/NRC Benchmark Based on NUPEC PWR Subchannel and Bundle Tests (PSBT). Volume II: Benchmark Results for the Void Distribution Phase," NEA/NSC/DOC, December 2011.

[6] A. Rubin and M. Avramova, "OECD/NRC Benchmark Based on NUPEC PWR Subchannel and Bundle Tests (PSBT). Volume III: Benchmark Results for the Departure from Nucleate Boiling Phase," NEA/NSC/DOC, December 2011.

[7] C. Baudry, M. Guingo, A. Douce et al., "OECD/NEA PSBT benchmark: simulation of the steady-state sub-channel testcase with NEPTUNE CFD," in Proceedings of the 14th International Topical Meeting on Nuclear Reactor Thermal-Hydraulics (NURETH-14), CD-ROM, Ontario, Canada, September 2011.

[8] T. Frank, F. Reiterer, and C. Lifante, "Investigation of the PWR subchannel void distribution benchmark (OECD/NRC PSBT Benchmark) using ANSYS CFX," in Proceedings of the 14th International Topical Meeting on Nuclear Reactor Thermal-Hydraulics (NURETH-14), CD-ROM, Ontario, Canada, September 2011.

[9] A. Del Nevo, L. Michelotti, D. Rozzia, F. Moretti, and F. D’Auria, "Void fraction prediction of NUPEC PSBT tests by CATHARE code," in Proceedings of the 14th International Topical Meeting on Nuclear Reactor Thermal-Hydraulics (NURETH-14), CD-ROM, Ontario, Canada, September 2011.

[10] T. W. Kim and A. Manera, "Prediction of void fraction in a subchannel and bundle geometry with FLICA4 and TRACE", in Proceedings of the 14th International Topical Meeting on Nuclear Reactor Thermal-Hydraulics (NURETH-14), CD-ROM, Ontario, Canada, September 2011.

[11] M. Valette, "Subchannel and rod bundle PSBT simulation with CATHARE-3," in Proceedings of the 14th International Topical Meeting on Nuclear Reactor Thermal-hydraulics (NURETH-14), CD-ROM, Ontario, Canada, September 2011.

[12] M. Bucci and P. Fillion, "Analysis of the NUPEC PSBT tests with FLICA-OVAP part 2: DNB benchmark," in Proceedings of the 14th International Topical Meeting on Nuclear Reactor Thermalhydraulics (NURETH-14), CD-ROM, Ontario, Canada, September 2011.

[13] A. Berkhan, V. Sánchez, and U. Imke, "Validation of PWRrelevant models of SUBCHANFLOW using the NUPEC PSBT data," in Proceedings of the 14th International Topical Meeting on Nuclear Reactor Thermal-hydraulics (NURETH-14), CD-ROM, Ontario, Canada, September 2011.

[14] D. H. Hwang, S. J. Kim, and K. W. Seo, "Analysis of PSBT benchmark exercises for void distribution and DNB using a subchannel code MATRA," in Proceedings of the 14th International Topical Meeting on Nuclear Reactor Thermal-hydraulics (NURETH-14), CD-ROM, Ontario, Canada, September 2011. 


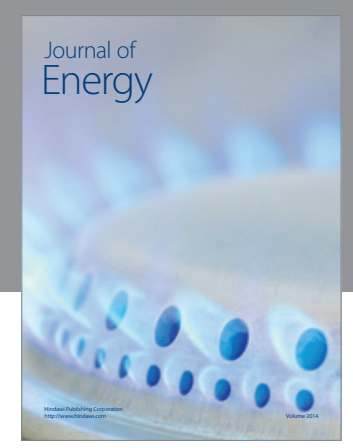

Journal of

Industrial Engineering
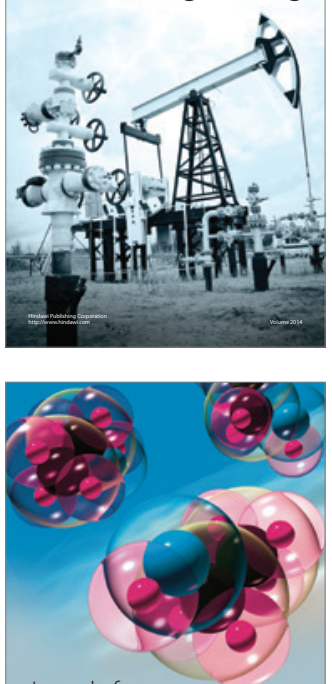

Fuels
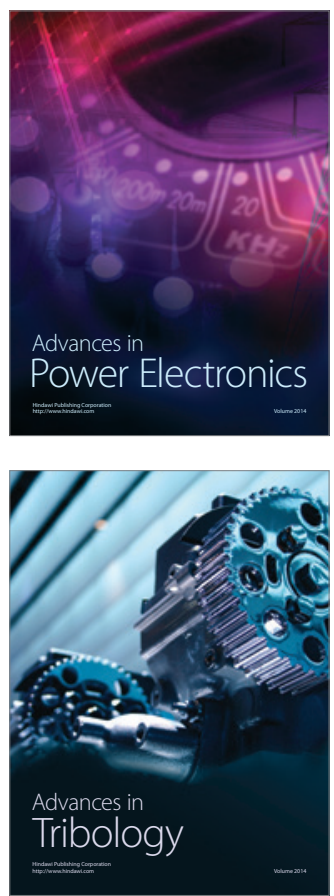

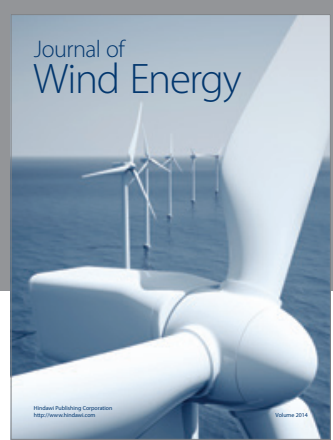

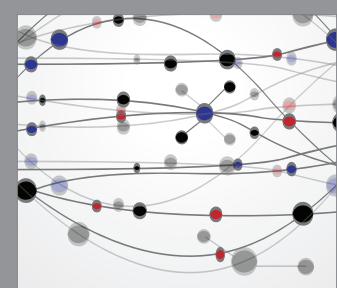

The Scientific World Journal

Submit your manuscripts at http://www.hindawi.com

Journal of

Structures
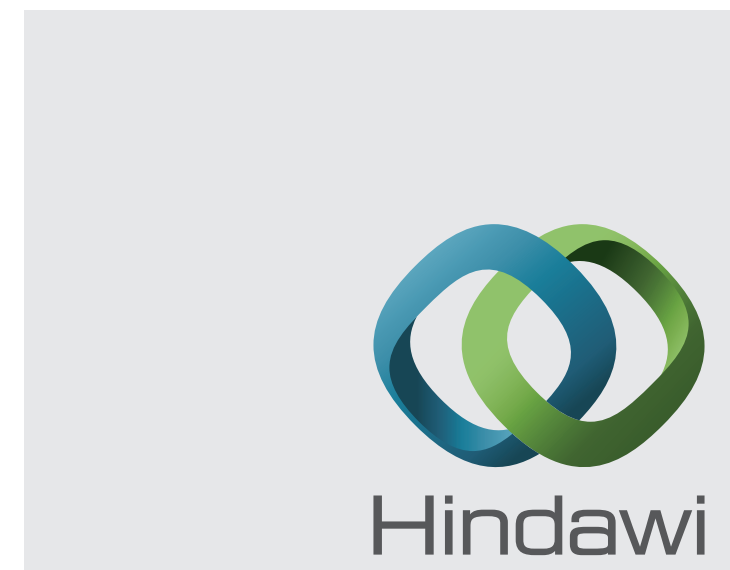

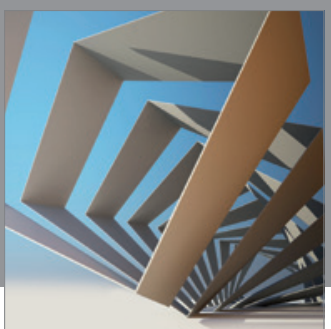

Rotating

Machinery
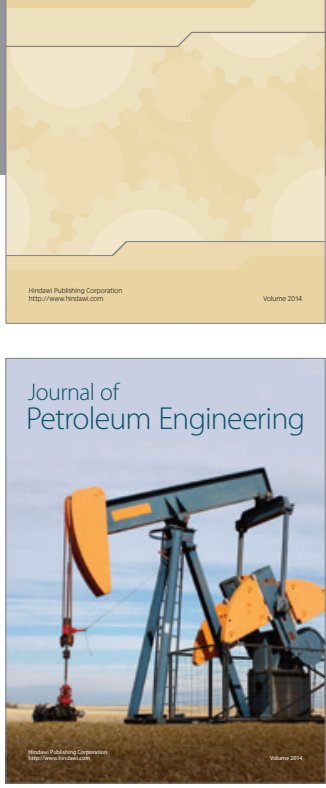

Journal of

Solar Energy
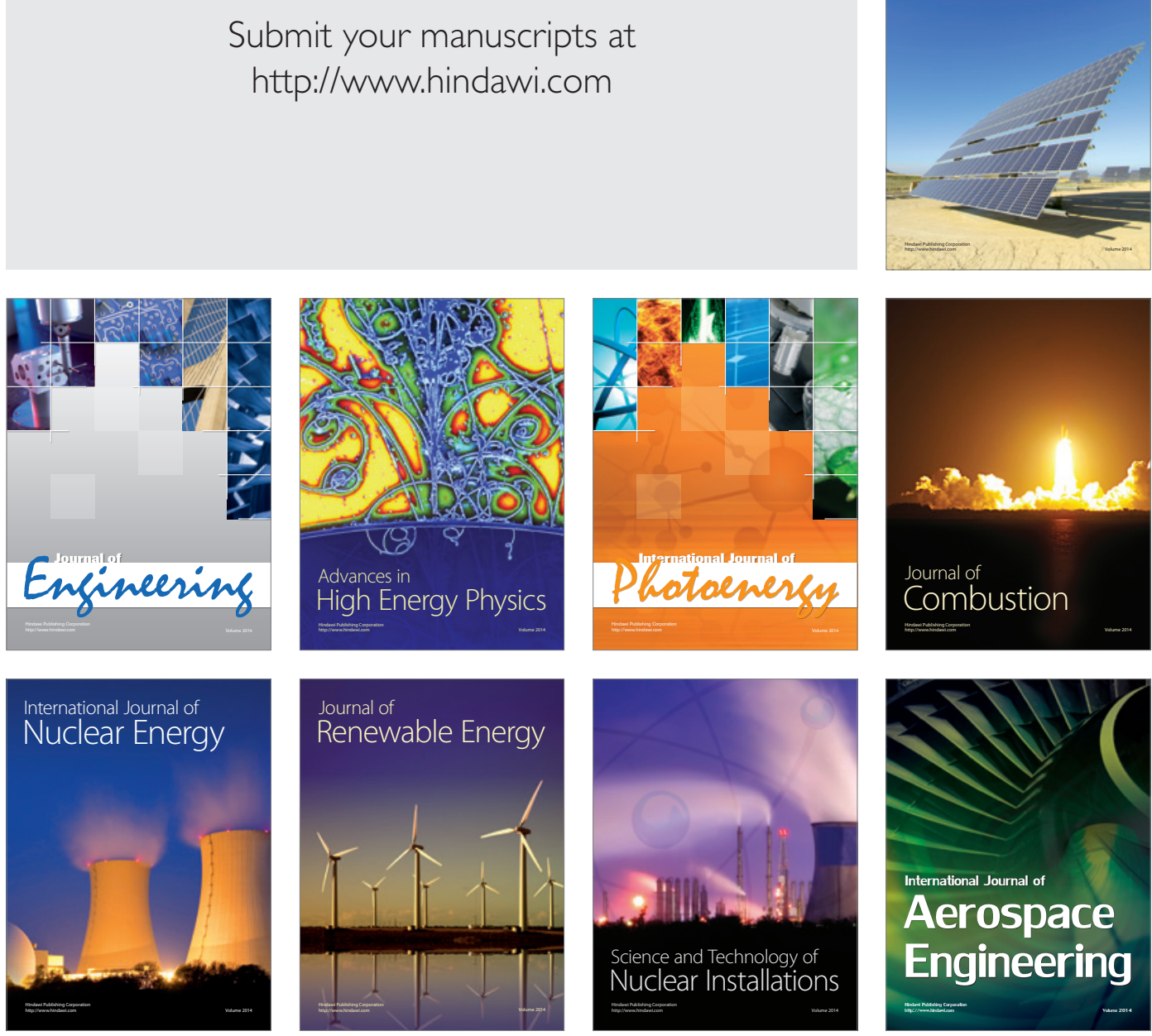